\title{
Mathematical modelling and optimization of surface quality and productivity in turning process of AISI 12L14 free-cutting Steel
}

\author{
B. Ben Fathallah ${ }^{a^{*}}$, R. Saidi ${ }^{b}$, C. Dakhli ${ }^{a}$, S. Belhadi ${ }^{c}$ and M. A. Yallese ${ }^{c}$
}

${ }^{a}$ Mechanical, Material and Process Laboratory (LR99ES05), University of Tunis El Manar,ENSIT, Tunis, 5 AV Taha Hussein Montfleury, Tunis, Tunisia

${ }^{b}$ Applied Mechanics and Engineering Laboratory (LR-11-ES19), University of Tunis El Manar, ENIT, BP 37, Le Belvédère, 1002 Tunis, Tunisia

${ }^{c}$ Mechanics and Structures Research Laboratory (LMS), May 8th 1945, University of Guelma, Algeria

\section{H R O N I C L E \\ A B S T R A C T}

Article history:

Received February 12019

Received in Revised Format

February 252019

Accepted March 142019

Available online

March 142019

Keywords:

AISI 12L14

Surface roughness

Cutting force

Optimization

Modeling

RSM

\begin{abstract}
In this study, several series of experiments on turning process of AISI 12L14 free cutting steel characterized by its self-lubrication and the high percentage of lead in its composition were performed to rate the influence of cutting conditions $\left(V_{c}, f\right.$ and $\left.a_{p}\right)$ on the machining performance such as surface roughness, cutting force, cutting power and material removal rate. A computer generated optimal design of experiment based on the I-optimality criteria along with analysis of variance was created to study the characterizations in turning of this steel, and desirability function was utilized for the optimization. The global optimization, combined high surface quality and productivity with low cutting power consumption, gave 12 optimal setting points provided high desirability values. The obtained correlation for surface roughness, cutting force, material removal rate and cutting power were $99.4 \%, 95.5 \%, 99.7 \%$ and $94.3 \%$, respectively.
\end{abstract}

(C) 2019 by the authors; licensee Growing Science, Canada

\begin{tabular}{|clll|}
\hline \multicolumn{2}{l}{ Nomenclature } & & \\
$\mathrm{V}_{\mathrm{c}}$ & cutting speed $(\mathrm{m} / \mathrm{min})$ & ANOVA & analysis of variance \\
$f$ & feed rate $(\mathrm{mm} / \mathrm{rev})$ & RSM & response surface methodology \\
$\mathrm{a}_{\mathrm{p}}$ & depth of cut $(\mathrm{mm})$ & $\mathrm{DF}$ & degrees of freedom \\
$\mathrm{R}_{\mathrm{a}}$ & arithmetic mean roughness $(\mu \mathrm{m})$ & Seq SS & sequential sum of squares \\
$\mathrm{Fc}$ & tangential force $(\mathrm{N})$ & Adj MS & adjusted mean squares \\
$\mathrm{Pc}$ & cutting power $(\mathrm{w})$ & Cont $\%$ & contribution ratio $(\%)$ \\
\hline
\end{tabular}

\section{Introduction}

The best machinability of AISI 12L14 free-cutting steel has awarded the materials such wide application in machinery, energy, metallurgy, aerospace, and other fields (Luiz \& Machado 2008; Pierson 1989; Yaguchi \& Bhattacharya 1988). The choice of using free-cutting steel in manufacturing processes forced the studies to converge towards the compromise, high productivity - better surface quality. The success

* Corresponding author

E-mail: brahim.benfathallah@enit.utm.tn (B. Ben Fathallah)

2019 Growing Science Ltd.

doi: $10.5267 /$ j. ijiec.2019.3.001 
of AISI 12L14 free-cutting steel lies in its low-carbon rate and particularly in the low melting point of lead particles that ensures inherent lubrication during the machining of the steel and embrittlement of the liquid metal (LME) at low machining speeds, and, thus avoids Built-Up-Edge (BUE) formation. In addition, the inclusions of phosphorus and sulfide form stress concentration source and discontinuity in the ferrite substrate, causing easy breakable chips. Moreover, the formed sulfide lubricant zone during the machining process reduces the frictions and the tool wear, which further enhance its machinability (Overcash \& Cuttino 2009). All these features combined make this material the highest machinable among all the common carbon and alloy steels. This machinability is assessed in terms of low cutting forces and good chip breaking characteristics (Reis et al., 2007; Roelofs et al., 2008; Yaguchi \& Bhattacharya, 1988).

However, machinability depends on the interaction tool - material - lubrication mode - cutting conditions and so forth (Bhattacharya \& Quinto 1980). Furthermore, the same material may have different degrees of machinability by adding some specific chemical elements such as tellurium (Yaguchi \& Onodera, 1988). As a result, there are many interacting parameters responsible for improving different machinability aspects including tool life, cutting force, surface finish and formation of small and stable built-up edges (Bouchelaghem et al., 2010; Kishawy et al., 2012; Peruchi et al., 2014; Song \& Zuo, 2014; $\mathrm{Xu}$ et al., 2012). In all machining processes, including turning, controlling the workpiece-tool interaction associated with the workpiece material is extremely difficult, especially when combining these parameters to study their effects on machinability and/or surface characteristics and their impact on service life (Costa et al., 2016; Fnides et al., 2011). Due to this complexity of combinations and their impact, we need to find a model for optimizing these parameters to expect a better quality and productivity. Generally, the quest is to optimize the cutting parameters, i.e. : feed rate, depth of cut and cutting speed, etc., in order to attain the minimum of surface roughness as an index of surface quality (Costa et al., 2016; Peruchi et al., 2014). The maximum of material removal rate and the minimum of cutting power as productivity and cost efficiency criterion (FNIDES et al., 2011; Kishawy et al., 2012; Kulekci et al., 2016). It is about performing a multi-objective optimization where the responses are correlated and may present conflicting results if each objective function is proceeded individually.

Many multi-objective optimization techniques are applied in this field. Among the common ones, the normal boundary intersection (NBI) method has been widely used. Introduced by Das and Dennis (1998), this method is based on generating Pareto surface for multi-objective optimization problems in turning of AISI 420 stainless steel (Bouzid et al., 2014). Despite its successful use for optimizing many nonlinear multi-objective problems, this method may lead to inappropriate results when the objectives are conflicting (Xu et al., 2012). To with draw this shortcoming, Costa et al. (2016) applied successfully a hybrid method combining Taguchi's signal-to-noise ratio (SNR) and principal component analysis (PCA) methods with the normal boundary intersection (NBI), to optimize the mean roughness, the total roughness and the material removal rate of AISI 12L14 free machining steel in turning process (Das \& Dennis, 1998; Dureja et al., 2010; Tebassi et al., 2016). They used response surface methodology RSM to generate the objective functions. In the same way, to overcome the weakness of Global Criterion Method (GCM) in taking under account the correlations between responses, Gomes et al. (2012) proposed a PCA based GCM approach to optimize arithmetic and total roughness (Ra, Rt), cutting time and material removal rate of AISI 12L14 free machining steel in turning process (Kishawy et al. 2012; Selvakumar et al., 2015). The applied method yielded to a one single constrained objective function. Then, the optimal point was found by applying a Genetic Algorithm. Bouzid et al. (2014) used Taguchibased grey relational analysis to, simultaneously, minimize surface roughness and maximize material removal rate for turning EN X20Cr13 stainless steel. The principle of this method is to convert a multiobjective problem into an easy-to-solve single objective one (Meddour et al., 2015). This method was proven applicable for different types of material and responses.

A Versatile and flexible RSM based method, which involves the use of desirability functions was successfully used in dealing with multi-objective optimization problems involving possible conflicting 
objectives. This method was proposed by (Saidi et al., 2018; Thangavel \& Selladurai, 2008). It has the advantages of coming up with solutions that satisfies each of the requirements without compromising too much on any of them, and giving a possible set of desirable solutions where the experimenter is up to choose the most convenient or feasible one. Sarıkaya and Güllü (2014) used this method to analyze machining parameters in CNC turning under MQL of AISI 1050 steel. They studied the impact of different MQL cooling flow rates and cutting parameters (feed rates, depths of cut and cutting speeds) on the surface roughness ( $\mathrm{Ra}$ and $\mathrm{Rz}$ ). This method was shown very accurate and useful tool for predicting surface roughness. Hwang and Lee performed comparative analysis between MQL and wet turning of AISI 1045 (Hwang \& Lee, 2010). They used fractional factorial design and desirability functions based optimizations to find the optimal cutting parameters and the cooling environment leading to simultaneous minima of surface roughness and the cutting force. Their study led to that the MQL turning was more likely to improve the surface quality. However, when it comes to cutting force, MQL and wet turning had quite the same effect. Therefore, they concluded the usefulness of switching from classical cooling conditions to MQL for its environmental and economic advantages. Meddour et al. (2015) used the same method to define the optimal machining parameters: feed rate $f$, depth of cut $a_{p}$, cutting speed $\mathrm{V}_{c}$, and tool nose radius ( $\mathrm{r}$ ) to minimize both cutting forces ( $\mathrm{Fx}, \mathrm{Fy}$ and $\mathrm{Fz}$ ) and the arithmetic roughness ( $\mathrm{Ra}$ ) in hard turning of AISI 52100 steel. As a result, they found a set of six possible combinations of optimal cutting parameters. Their investigations led to a conclusion that three of those parameters $\left(a_{p}, f\right.$ and $\left.r\right)$ must be fixed at their minimum and the $V_{c}$ must be chosen within six different values in order to reach the desired goal. The same method is also applied to optimize both the tool flank wear and surface roughness of hard turning AISI H11 steel (Sarıkaya \& Güllü, 2014). The applied optimization technique yielded to a range of eleven setting possibilities to achieve the highest surface quality with the lowest level of tool wear. Indeed, this method shows some flexibility over the other optimization techniques since it allows the operator to choose the most convenient setting of his process, among the given possibility.

The purpose of the present study is to optimize cutting conditions $\left(\mathrm{V}_{\mathrm{c}}\right.$, $\mathrm{f}$ and $\left.\mathrm{a}_{\mathrm{p}}\right)$ leading to maximum material removal rate MRR and minimum surface roughness $\mathrm{Ra}$ as well as cutting power $\mathrm{P}_{\mathrm{c}}$ in finish turning of AISI 12L14 free machining steel. The used optimization technique is the response surface methodology (RSM) based desirability function approach. A computer established optimal design using I-Optimality Criterion was used to perform a runs limited experimental campaign (Dureja et al., 2010). Amongst the few scientific works on AISI 12L14, dealing with the main subject of the present paper, we can cite the followings. Costa et al. (2016) by the use of a novel RSM and SNR-PCA-NBI Taguchi based approach, was able to find a single solution giving the optimum values of $V_{c}$, f and $a_{p}$ in order to minimize roughness ( $\mathrm{Ra}, \mathrm{Rt})$ and maximize material removal rate. Gomes et al. (2012) proposed a new PCA based GCM approach, in the same context (Salgado Jr et al., 2012). They both chose a central composite design with three factors at two levels to generate the experimental runs. Those studies focused on the methodology and the specifics of the developed optimization techniques, rather than the details about the effects of the input parameters and their interactions on the responses. The authors used the graphics of the main effects of input parameters, resulted from the analysis of variances (ANOVA), to determine the optimal value of each one that leads to the minimum of surface roughness (Kandananond, 2009; Saidi et al., 2018). Kandananond (2009) used the Box-Behnken design as a generator of the experiments matrix. In a further study dealing with the same topic, he used interactions and RSM (contours and 3D surface) graphs to both study deeply the effects of cutting parameters as well as their interactions on the surface roughness, and graphically define the optimal value of each one leading to the minimum of surface roughness (Kandananond, 2010). To carry out the set of experiments, he used a full factorial design (Saidi et al., 2018). This simple graphical method of optimization cannot be employed in multi objective problems with possible conflicting responses.

In our case study, the main characteristics of the process is the presence of correlation between responses, which have different optimization objectives. For example, while the roughness and the cutting power have to be minimized, the removal rate has to be maximized, and there is a possibility that one level of a 
certain parameter can fully satisfy one response criterion while it completely contradicts some others. Therefore, we selected the RSM based desirability function method, which is supposed to give us the possibility to adjust soundly the optimization process in order to have a set of solutions with high desirability values. The adjustments should be done after studying the responses individually. Thus, we will start by treating every response via the analysis of their corresponding interaction surface topographies to see how input parameters influence those responses, and the optimization of every response, individually. Based on the results of those pre-studies, we will be able to perform a proper global optimization.

\section{Experimental procedure}

\subsection{Process and material}

The turning experiments were performed on a TOS TRENCIN SN40C lathe machine with a spindle power of $6.6 \mathrm{~kW}$ and a spindle speed range of $20-2000 \mathrm{rpm}$. The used material in this study is AISI 12L14 steel (Fig.1). The chemical composition and mechanical properties are shown in Tables 1, 2, respectively. The microstructure of the tested material were composed predominantly of ferrite with minor amounts of pearlite, and additive inclusions of lead, manganese sulfide and carbon inclusions as shown in the micrograph realized on the optical NIKON microscope type FX-35WA (Fig.2). The turning operations were carried out, under dry conditions, by SANDVIK CVD coated ( $\left.\mathrm{Ti}(\mathrm{C}, \mathrm{N})+\mathrm{Al}_{2} \mathrm{O}_{3}+\mathrm{TiN}\right)$ inserts: ISO coded as SNMG 0903 04-PM 4315. The cutting inserts were mounted on an ISO DSBNL 1616H 09 tool holder.

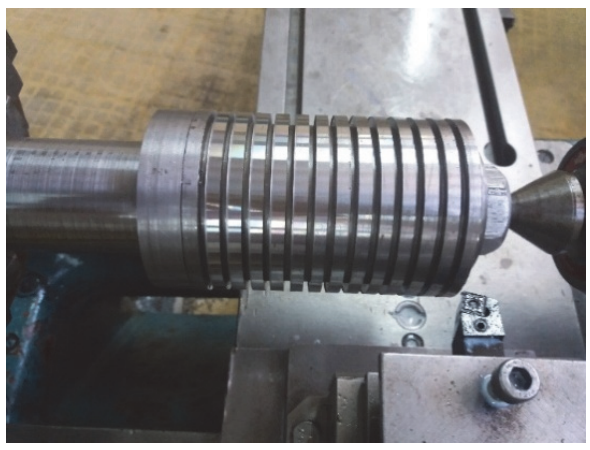

Fig. 1. Flow chart for the correction of the roll forming process design

[Table 1

Chemical composition (\%) of AISI 12L14 steel

\begin{tabular}{ccccccc}
\hline$C$ & $S i$ & $M n$ & $P$ & $S$ & $P b$ & $F e$ \\
\hline 0.079 & 0.032 & 1.258 & 0.072 & 0.36 & 0.296 & balance \\
\hline
\end{tabular}

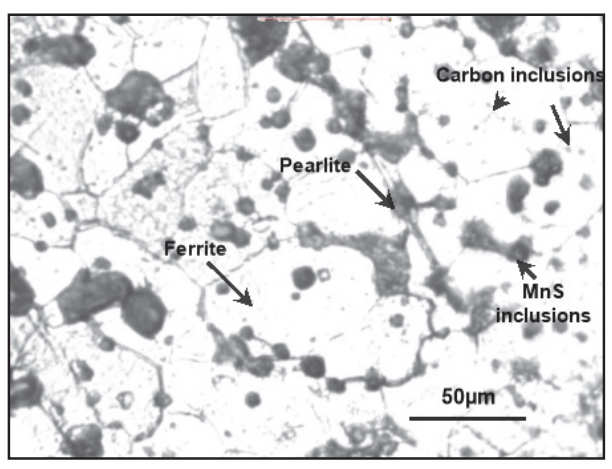

Fig. 2. Microstructure of free cutting steel AISI 12L14 (Optical micrograph)

Table 2

Mechanical properties of AISI 12L14 steel

\begin{tabular}{cccccc}
\hline $\begin{array}{c}\mathrm{Rm} \\
{[\mathrm{MPa}]}\end{array}$ & $\begin{array}{c}\mathrm{Rp}_{(0.2)} \\
{[\mathrm{MPa}]}\end{array}$ & $\begin{array}{c}\mathrm{Re} \\
{[\mathrm{MPa}]}\end{array}$ & $\begin{array}{c}\mathrm{A} \\
(\%)\end{array}$ & $\begin{array}{c}\text { Dureté } \\
\mathrm{HV}\end{array}$ & $\begin{array}{c}\mathrm{E} \\
{[\mathrm{GPa}]}\end{array}$ \\
\hline 650 & 440 & 400 & 8 & 190 & 200 \\
\hline
\end{tabular}

\subsection{Measurements and data acquisition}

The measurement of arithmetic mean roughness (Ra) was performed by means of a Mitutoyo SURFTEST SJ-210 roughness tester equipped with linearly moving $5 \mu \mathrm{m}$ diamond point. The examined length is 4 $\mathrm{mm}$ with a cutoff of $0.8 \mathrm{~mm}$. The measurements were repeated at three $120^{\circ}$ separated axial lines. The calculated mean values were considered in this study. The cutting forces were measured during the process with a 9257B model Kistler dynamometer connected to a charge amplifier (type 5011B) and a data acquisition system. The three-dimensional surface roughness were characterized with a 3D optical metrology platform modular 500 Altisurf. Illustration of the overall experimental procedure is given in Fig.3. 


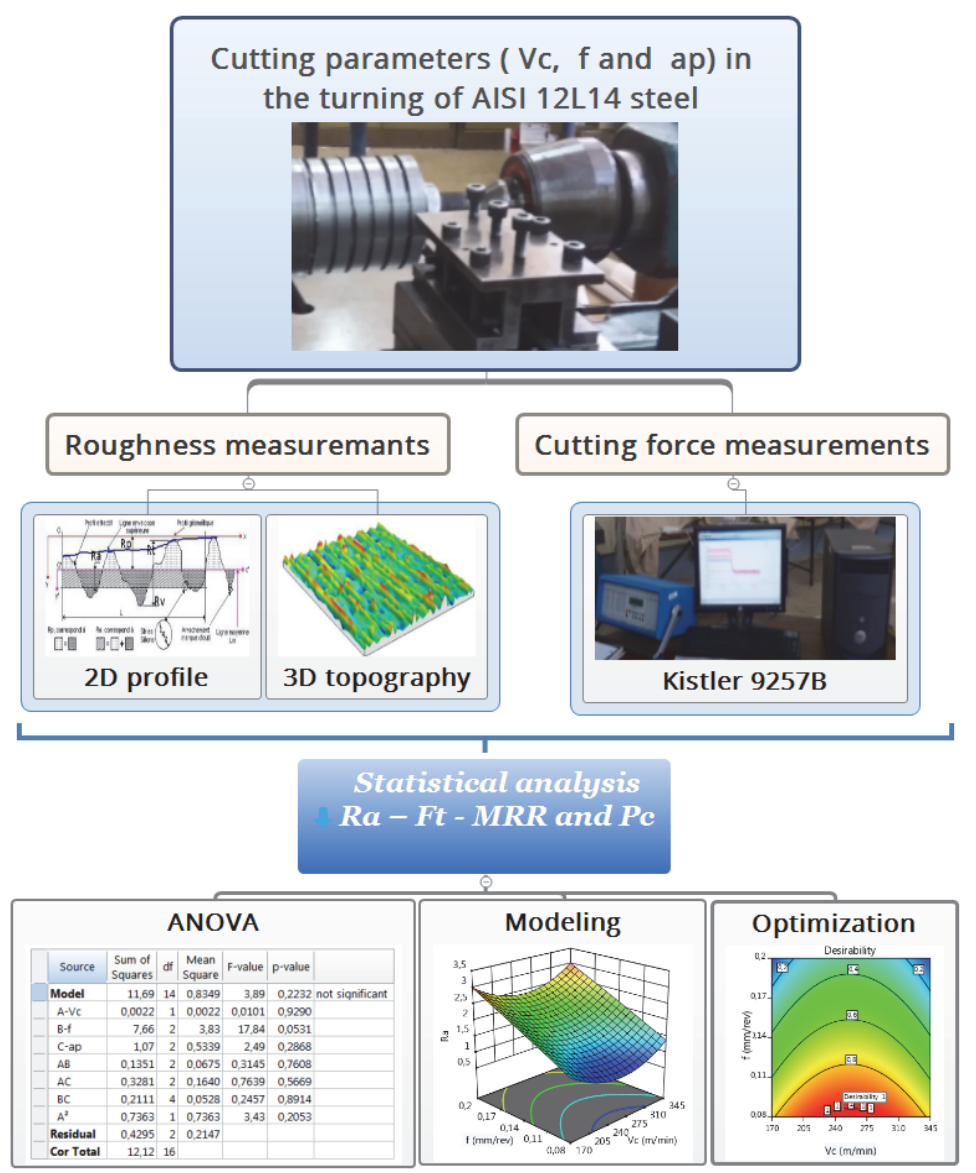

Fig. 3. Experimental procedure and data processing

\subsection{RSM method and design of experiments}

In order to develop the mathematical models based on RSM, an optimal computer generated design of experiment using I-optimality criterion is adopted. Cutting experiments are conducted considering three cutting parameters: feed rate ( $\mathrm{mm} / \mathrm{rev})$ Depth of Cut $(\mathrm{mm})$ and Cutting Speed $(\mathrm{m} / \mathrm{min})$. Table 3 shows the values of these parameters which are used in the experiments:

Table 2

Mechanical properties of AISI 12L14 steel

\begin{tabular}{cccc}
\hline Factors & \multicolumn{3}{c}{ Levels } \\
\cline { 2 - 4 } & 1 & 2 & 3 \\
\hline$V_{c},(\mathrm{~m} / \mathrm{min})$ & 175 & 245 & 345 \\
$f,(\mathrm{~mm} / \mathrm{rev})$ & 0.08 & 0.12 & 0.2 \\
$a_{p},(\mathrm{~mm})$ & 0.3 & 0.8 & 1.2 \\
\hline
\end{tabular}

In the present study, the second-order RSM-based mathematical models for surface roughness, cutting force, cutting power and material removal rate were developed with feed rate, depth of cut and cutting speed, as the cutting parameters. Using RSM, the effect of two or more cutting parameters on quality criteria can be investigated and optimum values could be obtained. In the analysis, the response (Y) was suggested by the second-order fitted polynomial regression model, also called the quadratic model, this model Y can be written as follows (Eq.(1)): 


$$
y=a_{0}+\sum_{i=1}^{3} a_{i} X_{i}+\sum_{i=1}^{3} a_{i i} X_{i}^{2}+\sum_{i=1}^{3} \sum_{j \geq i}^{3} a_{i j} X_{i} X_{j}+\varepsilon
$$

where $\mathrm{a}_{0}$ is constant, $\mathrm{a}_{\mathrm{i}}, \mathrm{a}_{\mathrm{ii}}$ and $\mathrm{a}_{\mathrm{ij}}$ are respectively, the coefficients of linear, quadratic and cross terms. $\mathrm{X}_{\mathrm{i}}$ reveals the coded variables. A commercial statistical analysis software DESIGN-EXPERT was employed to design and analyze the experiments. In DESIGN-EXPERT, RSM is used to find a combination of factors which gives the optimal response (Table 4). The aspects of machinability such as cutting power $\left(\mathrm{P}_{\mathrm{c}}\right)$ and material remove rate $(\mathrm{MRR})$ are calculated respectively as follows:

$$
\begin{aligned}
& P_{c}=\frac{F_{c} \times V_{c}}{60} \\
& M R R=V_{c} \times f \times V_{c}
\end{aligned}
$$

where $P_{c}$ is cutting power $(\mathrm{W}), F_{c}$ the tangential force $(N), f$ the feed rate $(\mathrm{mm} / \mathrm{rev}), a_{p}$ the depth of cut

\begin{tabular}{|c|c|c|c|c|c|c|c|}
\hline \multirow[b]{2}{*}{ Run } & \multicolumn{3}{|c|}{ Factors } & \multicolumn{4}{|c|}{ Responses } \\
\hline & $\begin{array}{c}V_{c} \\
(\mathrm{~m} / \mathrm{min})\end{array}$ & $\begin{array}{c}f \\
(\mathrm{~mm} / \mathrm{rev})\end{array}$ & $\begin{array}{c}a_{p} \\
(\mathrm{~mm})\end{array}$ & $\begin{array}{c}R_{a} \\
(\mu m)\end{array}$ & $\begin{array}{l}F_{c} \\
(N)\end{array}$ & $\begin{array}{c}P_{c} \\
(W)\end{array}$ & $\begin{array}{c}M R R \\
\left(\mathrm{~cm}^{3} / \mathrm{min}\right)\end{array}$ \\
\hline 1 & 345 & 0.12 & 0.3 & 1.56 & 147.83 & 850.01 & 12.42 \\
\hline 2 & 245 & 0.2 & 0.8 & 2.48 & 224.04 & 821.48 & 35.2 \\
\hline 3 & 175 & 0.2 & 1.2 & 3.17 & 374.67 & 1061.56 & 40.8 \\
\hline 4 & 175 & 0.08 & 0.3 & 1.24 & 67.6 & 191.53 & 4.08 \\
\hline 5 & 245 & 0.2 & 0.3 & 2.43 & 121.66 & 446.07 & 13.2 \\
\hline 6 & 175 & 0.12 & 0.8 & 1.93 & 188.6 & 534.37 & 16.32 \\
\hline 7 & 175 & 0.08 & 1.2 & 1.49 & 223.43 & 633.04 & 16.32 \\
\hline 8 & 345 & 0.12 & 1.2 & 2.3 & 221.47 & 1273.46 & 49.68 \\
\hline 9 & 245 & 0.08 & 0.8 & 0.98 & 171.09 & 627.33 & 14.08 \\
\hline 10 & 175 & 0.2 & 0.3 & 2.86 & 110.95 & 314.36 & 10.2 \\
\hline 11 & 345 & 0.08 & 1.2 & 1.83 & 128.33 & 737.9 & 33.12 \\
\hline 12 & 345 & 0.12 & 0.8 & 1.97 & 188.74 & 1085.26 & 33.12 \\
\hline 13 & 245 & 0.12 & 1.2 & 1.63 & 268.08 & 982.96 & 31.68 \\
\hline 14 & 345 & 0.2 & 0.8 & 3.07 & 275.8 & 1585.85 & 55.2 \\
\hline 15 & 245 & 0.12 & 0.3 & 1.29 & 89.56 & 328.4 & 7.92 \\
\hline 16 & 245 & 0.2 & 1.2 & 2.52 & 305.95 & 1121.81 & 52.8 \\
\hline 17 & 345 & 0.08 & 0.3 & 0.91 & 166.31 & 956.28 & 8.28 \\
\hline
\end{tabular}
$(\mathrm{mm}), \mathrm{V}_{\mathrm{c}}$ the cutting speed $(\mathrm{m} / \mathrm{min})$, and MRR the material removal rate $\left(\mathrm{cm}^{3} / \mathrm{min}\right)$

\section{Table 4}

Experimental runs and results for Ra, Fc, Pc and MRR

\section{Results and discussion}

\subsection{Statistical analysis and validation of $F c, M R R, P c$ and $R a$}

\subsubsection{ANOVA}

The results of the Variance Analysis (ANOVA) were employed to determine the factors significantly affecting measurement performance. The resulted ANOVA tables of each response (Tables (5-8)) consist of sums of squares and degrees of freedom. The sum of squares is performed into contributions to the polynomial model as well as the experimental value and was determined with the following (Eq.(4)):

$$
S S_{f}=\frac{N}{N_{n f}} \sum_{i=1}^{N_{n f}}\left(\overline{y_{i}}-\bar{y}\right)^{2}
$$

The mean square was expressed by the following Eq. (5) where (MS) represents the squares sum ratio to degrees of freedom:

$$
M S=\frac{M S_{i}}{M S_{e}}
$$


The percentage of each factor contribution (Cont. \%) was calculated by the Eq.(6). This is displayed in column 8 of the ANOVA tables

$$
\text { Cont } \%=\frac{S S_{f}}{S S_{T}} \times 100
$$

To better view the results of the analysis of variance, Pareto charts were used (Figs. (4-7)), which rank the cutting parameters and their interactions on the surface roughness, cutting force, material removal rate and cutting power. The effects are standardized (F-value) for a better comparison, If the (F-value) values are greater than $(\mathrm{F}$-table $=2.36)$, the effects are significant. If the values of F-value are less than (2.36), the effects are not significant. The chosen confidence interval is $95 \%$. According to the analysis of variance (from ANOVA, Tables (5-8)), the ratios between the models' regression mean squares and their errors: (F-Values), for $\mathrm{R}_{\mathrm{a}}, \mathrm{F}_{\mathrm{c}}, \mathrm{MRR}$ and $\mathrm{P}_{\mathrm{c}}$, are, respectively, 88.77, 17.01, 281.24 and 11.64. Moreover, the "Prob $>F$ ", indicating the chances that F-Values those larges occur due to noise, are less than $0.01 \%$ for all the responses. Hence, it can be inferred that the utilized models are significant. The ANOVA results for the arithmetic mean surface roughness $R_{a}$ (Table 5) shows that the main model terms $f$ and $a_{p}$, the interaction $V_{c} \times a_{p}$, and the squared term $V_{c}{ }^{2}$ are highly significant as their "Prob $>F^{\prime}$ values are less than $0.01 \%$. The most influential factor among them is the feed rate $\mathrm{f}$ with a contribution of $74.25 \%$. The depth of cut $\mathrm{a}_{\mathrm{p}}$ and the product $\mathrm{V}_{\mathrm{c}}{ }^{2}$ are less prominent; they contribute in the model, respectively by $7.18 \%$ and 10.69 . The main input term $V_{c}$ is considered to be very insignificant as well as the remaining terms.

By the same way, according to the ANOVA results for cutting force $F_{c}$ presented in Table 6 , it can be stated that the feed rate $f$, the depth of cut $a_{p}$ and the interactions $V_{c} \times a_{p}$ and $f \times a_{p}$ are relevant terms. By contributing with $51.39 \%$, the term $a_{p}$ has the most statistically significance, followed by the feed rate $(16.3 \%)$, then $\mathrm{V}_{c} \times \mathrm{a}_{\mathrm{p}}(10.29 \%)$ and finally $\mathrm{f} \times \mathrm{a}_{\mathrm{p}}(4.64 \%)$. Although, $\mathrm{V}_{\mathrm{c}}$, as a main input term is found to be insignificant in this case, as well as its interaction with $\mathrm{f}\left(\mathrm{V}_{\mathrm{c}} \times \mathrm{f}\right)$. For the material removal rate MRR, it is shown, in Table 7 that the parameters $V_{c}$, $f$ and $a_{p}$ and the interactions $V_{c} \times f, V_{c} \times a_{p}$ and $f \times a_{p}$ are all significant sources. The highest amount of contribution occurs from the depth of cut with $55.51 \%$, In the second place comes the feed rate with $25.51 \%$ followed by the cutting speed $\mathrm{V}_{\mathrm{c}}$ with $16.23 \%$. Whereas the interaction $\mathrm{V}_{\mathrm{c}} \times f, \mathrm{~V}_{\mathrm{c}} \times \mathrm{a}_{\mathrm{p}}$ and $\mathrm{f} \times \mathrm{a}_{\mathrm{p}}$ contribute $1.93 \%, 2.67 \%$ and $4.38 \%$, respectively. Table 8 representing ANOVA for the resulting cutting power shows that the main input parameters $\left(\mathrm{V}_{\mathrm{c}}, \mathrm{f}\right.$ and $\left.\mathrm{a}_{\mathrm{p}}\right)$ are all statistically significant terms in the model. While, their interactions $\left(V_{c} \times f, V_{c} \times a_{p}\right.$ and $\left.f \times a_{p}\right)$ and squares $\left(\mathrm{V}_{\mathrm{c}}{ }^{2}, \mathrm{f}^{2}\right.$ and $\left.\mathrm{a}_{\mathrm{p}}{ }^{2}\right)$ are insignificant. The cutting speed, now, becomes the most significant term, as it is a factor constituting the cutting power formula (Eq.(2)), Its contribution reaches the $37.41 \%$. Positioned in the second rank, the depth of cut remains as one of the most important terms with $28.14 \%$ of influence, simply because it represents the highest contributing term in the model of the cutting force, which is a major component in the cutting power expression. Then, with quite less degree of influence, the feed rate contributes with $15.17 \%$.

Table 5

Analysis of variance for surface roughness

\begin{tabular}{|c|c|c|c|c|c|c|c|}
\hline Source & $\begin{array}{l}\text { Sum of } \\
\text { Squares }\end{array}$ & $d f$ & $\begin{array}{l}\text { Mean } \\
\text { Square }\end{array}$ & $\begin{array}{c}F \\
\text { Value }\end{array}$ & $\begin{array}{l}\text { p-value } \\
\text { Prob }>F\end{array}$ & Significance & $\begin{array}{c}\text { Contribution } \\
\%\end{array}$ \\
\hline Model & 7.89 & 9 & 0.87 & 88.77 & $<0.0001$ & Significant & \\
\hline$V_{c}$ & $5.6 \mathrm{E}-07$ & 1 & $5.6 \mathrm{E}-07$ & $0.1 \mathrm{E}-03$ & 0.99 & Not significant & 0 \\
\hline$f$ & 5.91 & 1 & 5.91 & 598.79 & $<0.0001$ & Significant & 74.25 \\
\hline$a_{p}$ & 0.57 & 1 & 0.57 & 57.91 & $<0.0001$ & Significant & 7.18 \\
\hline$V_{c} \times f$ & $1.48 \mathrm{E}-06$ & 1 & $1.48 \mathrm{E}-06$ & $0.1 \mathrm{E}-03$ & 0.99 & Not significant & 0 \\
\hline$V_{c} \times a_{p}$ & 0.11 & 1 & 0.11 & 11.3 & 0.012 & Significant & 1.4 \\
\hline$f \times a_{p}$ & 0.022 & 1 & 0.022 & 2.3 & 0.17 & Not significant & 0.29 \\
\hline$V_{c}^{2}$ & 0.85 & 1 & 0.85 & 86.15 & $<0.0001$ & Significant & 10.69 \\
\hline$f_{c}$ & $7 \mathrm{E}-04$ & 1 & $7 \mathrm{E}-04$ & 0.0713 & 0.79 & Not significant & 0.01 \\
\hline$a_{p}^{2}$ & $5 \mathrm{E}-04$ & 1 & $5 \mathrm{E}-04$ & 0.05 & 0.82 & Not significant & 0.01 \\
\hline $\begin{array}{l}\text { Residual } \\
\text { Cor Total }\end{array}$ & $\begin{array}{l}0.069 \\
7.96\end{array}$ & $\begin{array}{c}7 \\
16 \\
\end{array}$ & 0.01 & & & & \\
\hline Std. Dev. & 0.0994 & & R-Squared & 0.991 & & & \\
\hline
\end{tabular}


Table 6

Analysis of variance for cutting force

\begin{tabular}{cccccccc}
\hline Source & $\begin{array}{c}\text { Sum of } \\
\text { Squares }\end{array}$ & $d f$ & $\begin{array}{c}\text { Mean } \\
\text { Square }\end{array}$ & $\begin{array}{c}F \\
\text { Value }\end{array}$ & $\begin{array}{c}p \text {-value } \\
\text { Prob }>F\end{array}$ & Significance & $\begin{array}{c}\text { Contribution } \\
\%\end{array}$ \\
\hline Model & $1,02 \mathrm{E}+05$ & 9 & 11322.04 & 17.01 & 0.0005 & significant & \\
\hline$V_{c}$ & 112.25 & 1 & 112.25 & 0.16 & 0.7 & not significant & 0.11 \\
$f$ & $17.4 \mathrm{E}+03$ & 1 & $17.4 \mathrm{E}+03$ & 26.11 & 0.0014 & significant & 16.3 \\
$a_{p}$ & $54.83 \mathrm{E}+03$ & 1 & $54.83 \mathrm{E}+03$ & 82.33 & $<0.0001$ & significant & 51.39 \\
\hline$V_{c} \times f$ & 74.15 & 1 & 74.15 & 0.11 & 0.74 & not significant & 0.07 \\
$V_{c} \times a_{p}$ & $10.98 \mathrm{E}+03$ & 1 & $10.98 \mathrm{E}+03$ & 16.49 & 0.0048 & significant & 10.29 \\
$f^{\circ \times a_{p}}$ & $49.52 \mathrm{E}+02$ & 1 & $49.2 \mathrm{E}+02$ & 7.43 & 0.029 & significant & 4.64 \\
\hline$V_{c}{ }^{2}$ & 636.12 & 1 & 636.12 & 0.95 & 0.36 & not significant & 0.6 \\
$f^{2}$ & 24.04 & 1 & 24.04 & 0.036 & 0.85 & not significant & 0.02 \\
$a_{p}{ }^{2}$ & 167 & 1 & 167 & 0.26 & 0.63 & not significant & 0.16 \\
\hline Residual & 4662.47 & 7 & 666 & & & & \\
Cor Total & $1,07 \mathrm{E}+05$ & 16 & & & & & \\
\hline Std. Dev. & 25.91 & & R-Squared & 0.955 & & &
\end{tabular}

Table 7

Analysis of variance for Material Removal Rate

\begin{tabular}{|c|c|c|c|c|c|c|c|}
\hline Source & $\begin{array}{l}\text { Sum of } \\
\text { Squares }\end{array}$ & $d f$ & $\begin{array}{c}\text { Mean } \\
\text { Square }\end{array}$ & $\begin{array}{c}F \\
\text { Value }\end{array}$ & $\begin{array}{c}p \text {-value } \\
\text { Prob }>F\end{array}$ & Significance & $\begin{array}{c}\text { Contribution } \\
\%\end{array}$ \\
\hline Model & 4601.6 & 9 & 511.25 & 281.24 & $<0.0001$ & Significant & \\
\hline$V_{c}$ & 784.76 & 1 & 784.76 & 411.86 & $<0.0001$ & Significant & 16.23 \\
\hline$f$ & 1177.34 & 1 & 1177.34 & 647.6 & $<0.0001$ & Significant & 25.51 \\
\hline$a_{p}$ & 2561.39 & 1 & 2561.39 & 1408.91 & $<0.0001$ & Significant & 55.51 \\
\hline$V_{c} \times f$ & 89.15 & 1 & 89.15 & 49.04 & 0.0002 & Significant & 1.93 \\
\hline$V_{c} \times a_{p}$ & 123.26 & 1 & 123.26 & 67.8 & $<0.0001$ & Significant & 2.67 \\
\hline$f \times a_{p}$ & 202.14 & 1 & 202.14 & 111.19 & $<0.0001$ & Significant & 4.38 \\
\hline$V_{c}^{2}$ & 22.87 & 1 & 22.87 & 12.58 & 0.009 & significant & 0.5 \\
\hline $\begin{array}{l}c \\
f^{2}\end{array}$ & 0.05 & 1 & 0.05 & 0.027 & 0.87 & not significant & 0 \\
\hline$a_{p}^{2}$ & 0.247 & 1 & 0.247 & 0.136 & 0.72 & not significant & 0.01 \\
\hline Residual & 12.73 & 10 & 1.82 & & & & \\
\hline Cor Total & 4614.33 & 16 & & & & & \\
\hline Std. Dev. & 1.35 & & R-Squared & 0.997 & & & \\
\hline
\end{tabular}

Table 8

Analysis of variance for cutting power

\begin{tabular}{|c|c|c|c|c|c|c|c|}
\hline Source & $\begin{array}{l}\text { Sum of } \\
\text { Squares }\end{array}$ & $d f$ & $\begin{array}{l}\text { Mean } \\
\text { Square }\end{array}$ & $\begin{array}{c}F \\
\text { Value }\end{array}$ & $\begin{array}{c}p \text {-value } \\
\text { Prob }>F\end{array}$ & Significance & $\begin{array}{c}\text { Contribution } \\
\%\end{array}$ \\
\hline Model & $2.1 \mathrm{E}+06$ & 9 & $2.34 \mathrm{E}+05$ & 11.64 & $<0.0001$ & Significant & \\
\hline$V_{c}$ & $8.39 \mathrm{E}+05$ & 1 & $8.39 E+05$ & 41.82 & $<0.0001$ & Significant & 37.41 \\
\hline$f$ & $3.4 \mathrm{E}+05$ & 1 & $3.4 \mathrm{E}+05$ & 16.95 & 0.004 & Significant & 15.17 \\
\hline$a_{p}$ & $6.31 \mathrm{E}+05$ & 1 & $6.31 \mathrm{E}+05$ & 31.46 & $<0.0001$ & Significant & 28.14 \\
\hline$V_{c} \times f$ & $5.1 \mathrm{E}+04$ & 1 & $5.1 \mathrm{E}+04$ & 2.55 & 0.15 & not significant & 2.28 \\
\hline$V_{c} \times a_{p}$ & $5.85 \mathrm{E}+04$ & 1 & $5.85 E+04$ & 2.92 & 0.13 & not significant & 2.61 \\
\hline$f \times a_{p}$ & $7.8 \mathrm{E}+04$ & 1 & $7.8 \mathrm{E}+04$ & 3.89 & 0.089 & not significant & 3.48 \\
\hline$V_{c}^{2}$ & $6.34 E+04$ & 1 & $6.34 \mathrm{E}+04$ & 3.16 & 0,118 & not significant & 2.83 \\
\hline$f^{2}$ & 355.09 & 1 & 355.09 & 0.017 & 0,89 & not significant & 0.02 \\
\hline$a_{p}{ }^{2}$ & 4086.26 & 1 & 4086.26 & 0.2 & 0,66 & not significant & 0.18 \\
\hline Residual & $1.4 \mathrm{E}+05$ & 10 & $2 E+04$ & & & & \\
\hline Cor Total & $2.24 \mathrm{E}+06$ & 16 & & & & & \\
\hline Std. Dev. & 141.61 & & R-Squared & 0.937 & & & \\
\hline
\end{tabular}

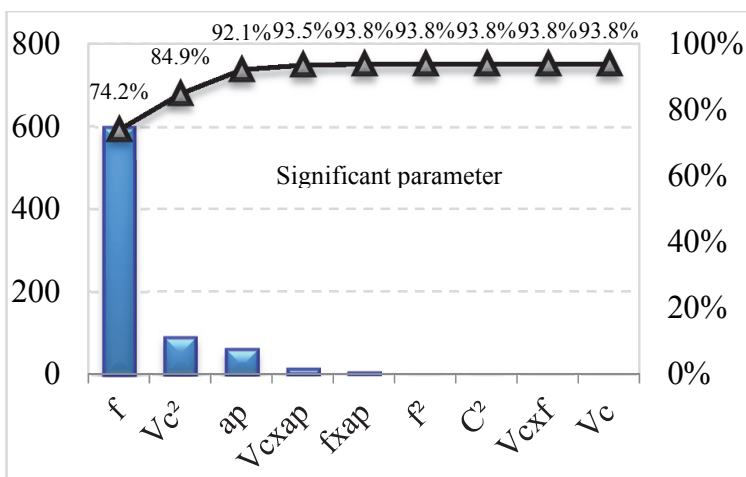

Fig. 4. Pareto chart of the standardized effects on surface roughness $(\alpha=0,05)$

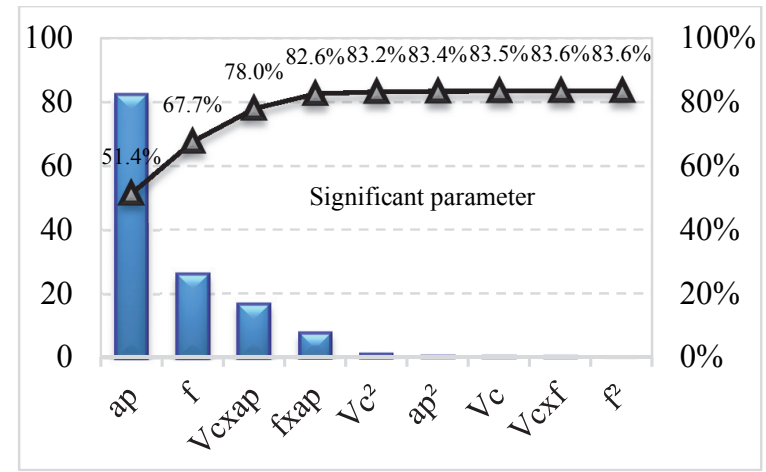

Fig. 5. Pareto chart of the standardized effects on cutting force $(\alpha=0,05)$ 


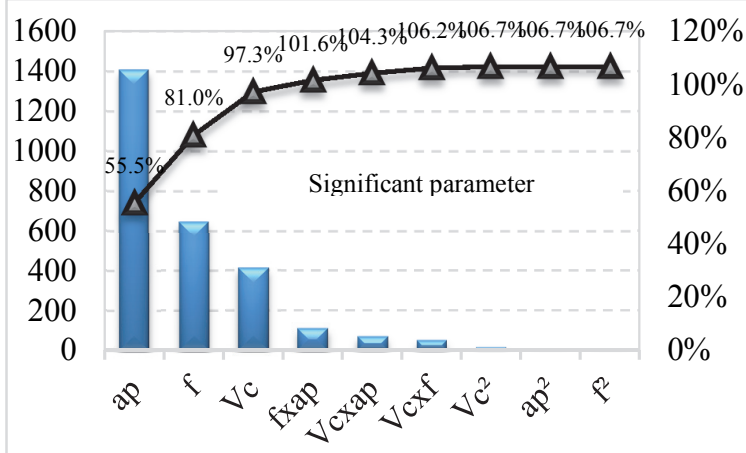

Fig. 6. Pareto chart of the standardized effects on material removal rate $(\alpha=0,05)$

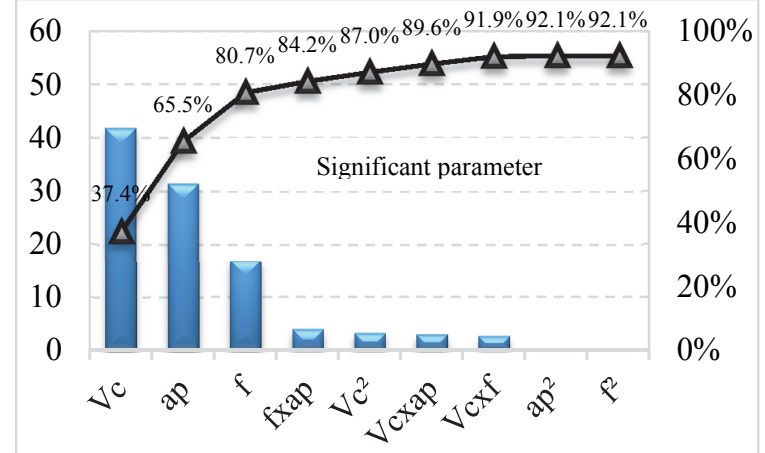

Fig. 7. Pareto chart of the standardized effects on cutting power $(\alpha=0,05)$

\subsubsection{Regression equations}

Second order regression models were implemented to obtain the correlation between the machining parameters (cutting speed, feed rate and depth of cut) and the measured surface roughness, cutting force, material removal rate and cutting power. The obtained correlation equations were as follows with respective coefficients of determination $\mathrm{R}^{2}$ of $99.4 \%, 95.5 \%, 99.7 \%$ and $94.3 \%$ :

Surface roughness

$R_{a}=4.494-0.038 \times V_{c}+16.236 \times f+0.026 \times a_{p}-0.000102 \times V_{c} \times f+0.00329 \times V_{c} \times a_{p}-2.07 \times f \times a_{p}+7 . E-5 \times$

$V_{c}^{2}-4.47 \times f^{2}-0.065 \times a_{p}^{2}$

cutting force

$F_{c}=-16.73-0.28 \times V_{c}+43.1 \times f+342.42 \times a_{p}+0.71 \times V_{c} \times f-1.03 \times V_{c} \times a_{p}+970.25 \times f \times a_{p}+1.91 . E-3 \times V_{c}{ }^{2}-$ $825.76 \times f^{2}-37.87 \times a_{p}^{2}$

\section{Material Removal Rate}

$M R R=39.03-0.273 \times V_{c}-152.66 \times f-20.69 \times a_{p}+0.78 \times V_{c} \times f+0.109 \times V_{c} \times a_{p}+196.02 \times f \times a_{p}+3.63 E-4 \times$

$V_{c}^{2}-37.45 \times f^{2}-1.45 \times a_{p}^{2}$

Cutting power

$P_{c}=+729.19-7.18 \times V_{c}-3697.2 \times f+880 \times a_{p}+18.8 \times V_{c} \times f-2.38 \times V_{c} \times a_{p}+3852.3 \times f \times a_{p}+0.019 \times V_{c}^{2}-$

$3174.9 \times f^{2}-187.31 \times a_{p}^{2}$

\subsubsection{Graphical validation}

These figures indicate that the quadratic models are capable of representing the system under the given experimental domain. The differences between measured and predicted responses are shown in Figs. (811). It reveals that from previous figures demonstrate that quadratic models can represent the system in the given experimental

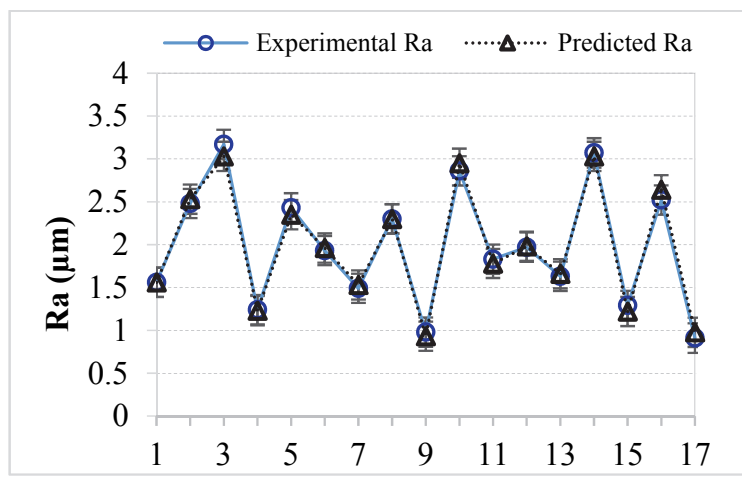

Fig. 8. Comparison between measured and predicted values for surface

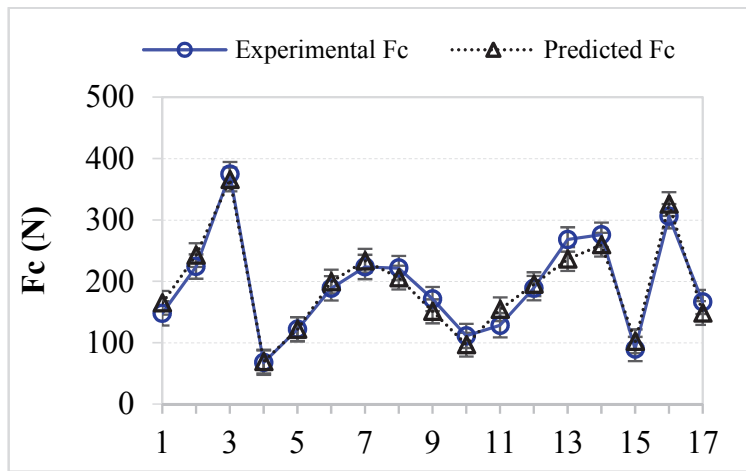

Fig. 9. Comparison between measured and predicted values for cutting force 


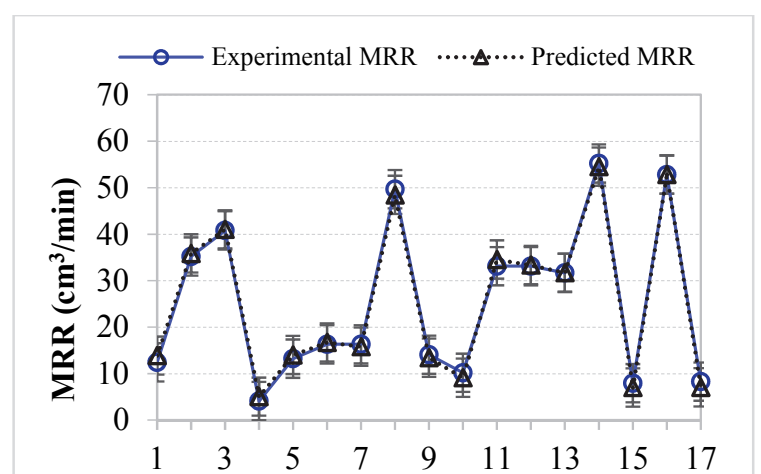

Fig. 10. Comparison between measured and predicted values for material removal rate

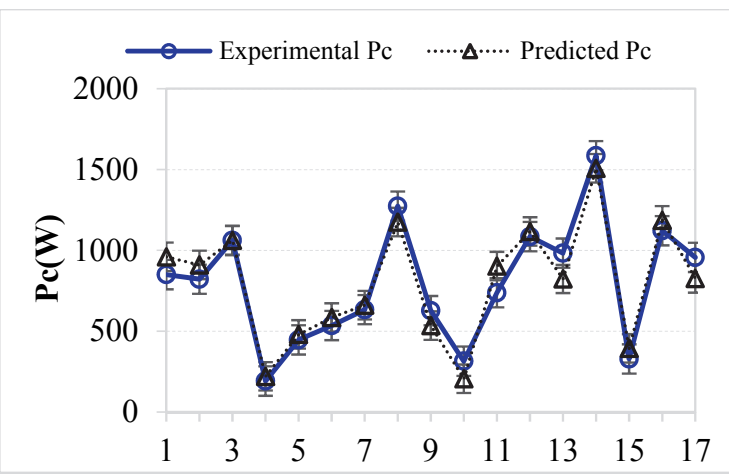

Fig. 11. Comparison between measured and predicted values for cutting power

The normal probability plots (Figs. (12-15)) of the residuals follow straight-line patterns, which indicate that errors are distributed normally. Consequently, it can be inferred that all the proposed models are adequate in term of normality and significance.

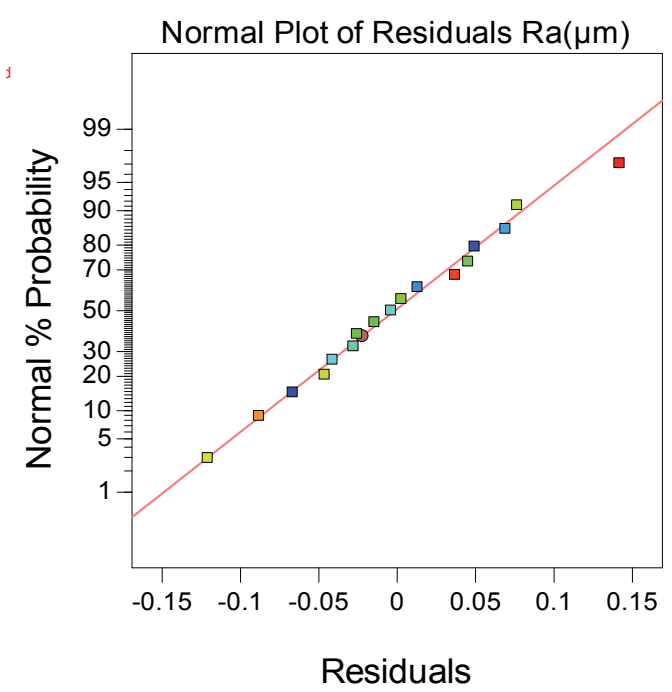

Fig. 12. Normal probability plots for surface roughness Normal Plot of Residuals MRR $\left(\mathrm{cm}^{\wedge} 3 / \mathrm{min}\right)$

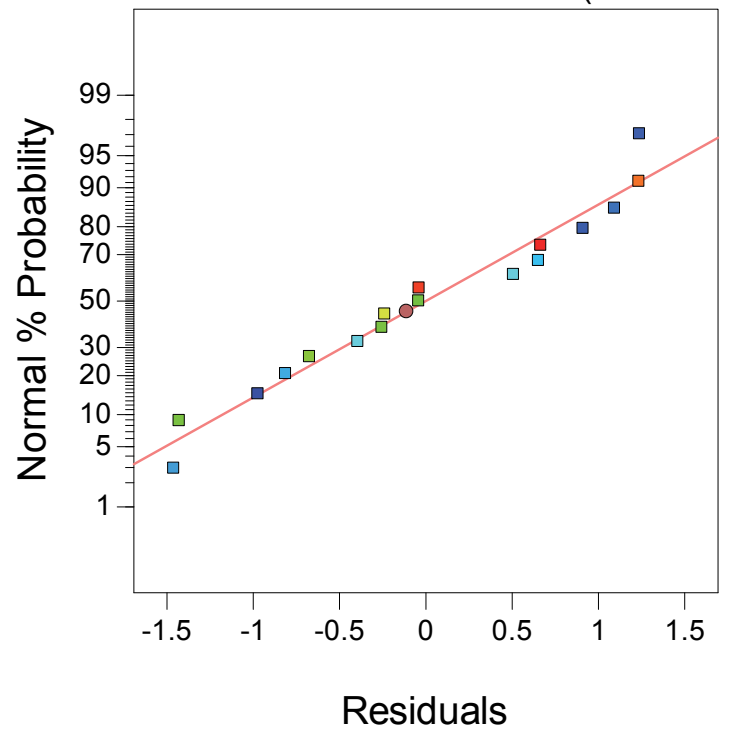

Fig. 14. Normal probability plots for material removal rate

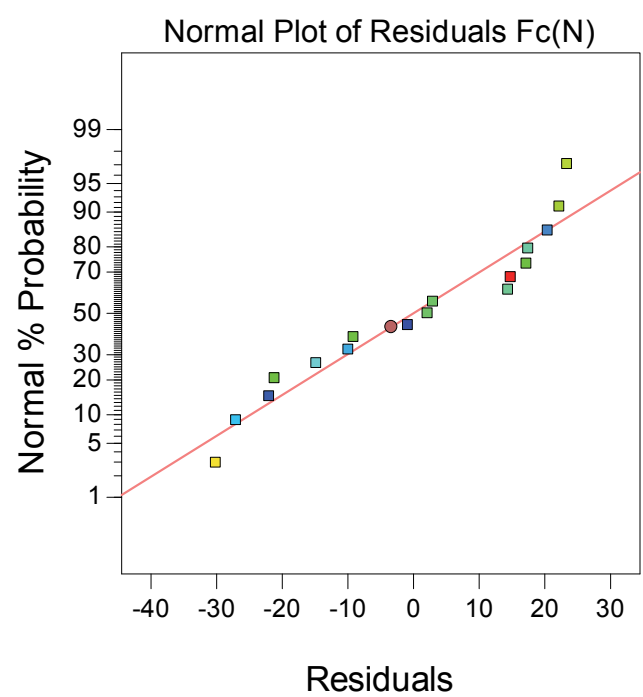

Fig. 13. Normal probability plots for cutting force. Normal Plot of Residuals Pc(W)

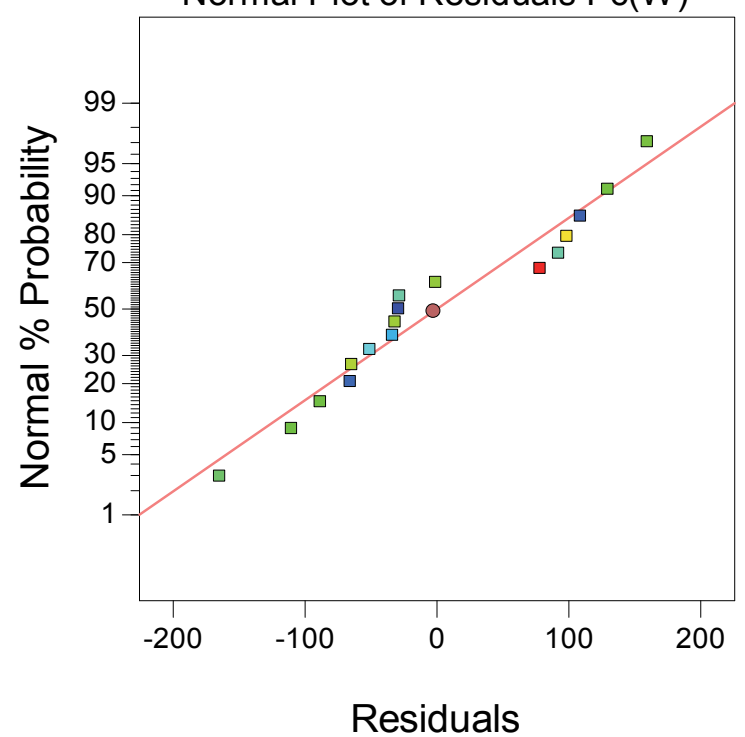

Fig. 15. Normal probability plots for cutting power 


\subsection{Effect of cutting parameters on surface quality}

The influence of machining parameters $\left(\mathrm{V}_{\mathrm{c}}, \mathrm{f}\right.$ and $\left.\mathrm{a}_{\mathrm{p}}\right)$ and their interaction effects on cutting force, material removal rate, cutting power, surface roughness, microhardness and chip formation can be analyzed by using 3D surface plots and 2D contours graph.

\subsubsection{Effect on surface roughness}

According to the 3D and 2Dcontour graphs of interactions (Figs.(16, 17)), it is quite clear that, in the given experimental interval, the contribution of the feed rate is the most preponderant when interacts with the cutting speed or with the depth of cut. It can be noted, visibly, that surface roughness increases with the feed rate. The predominance of $f$ while interact with $a_{p}$ or $V_{c}$ is well confirmed by the analysis of the variance (Table 5) which suggests a significance of against negligible effects of $f-V_{c}$ and $f-a_{p}$. Analysis of the 3D and 2D graphs (Fig. 18) of the $\left(a_{p}-V_{c}\right)$ interaction shows that, for a given feed rate, the roughness increases with the depth of cut, whatever the value of the cutting speed. We can also conclude that the increase in $\mathrm{V}_{\mathrm{c}}$ improves the surface quality to a certain limit from which the surface begins to increasingly degenerate. In fact, when cutting speed begins to increase, higher friction between the tool and the workpiece contact surface occurs. Thus, a local heating is generated, which locally softens the material and the dispersed lead particles. The softened insoluble lead's particles associated with sulfides will act as a lubricant film (Early J. 1984). Consequently, the material flows easily and without tearing, which finally gives a good surface quality. However, when the cutting speed increases further, the vibrations from the utilized conventional machine may increases. Since the material's contact surface is softened, the vibratory impact will be more striking, which ultimately results in a degraded surface quality. As an outcome from this analysis, it can be inferred that, for a better surface quality without taking under account the constraints of productivity and energy consumption, the feed rate has to be is set at its minimum, and then the depth of cut must be as low as possible with an average cutting speed within the current experimental area.
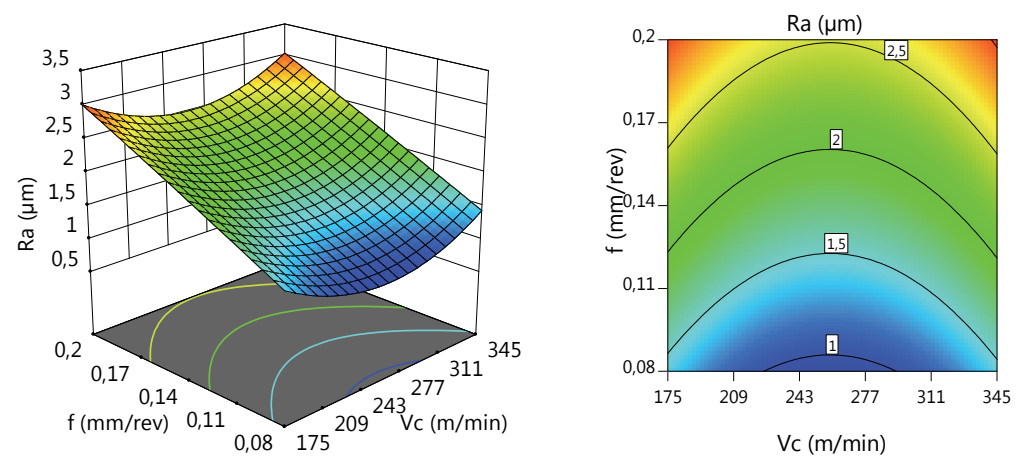

Fig. 16. Effect of cutting speed and feed rate on surface roughness, with depth of cut $a_{p}=0.8 \mathrm{~mm}$
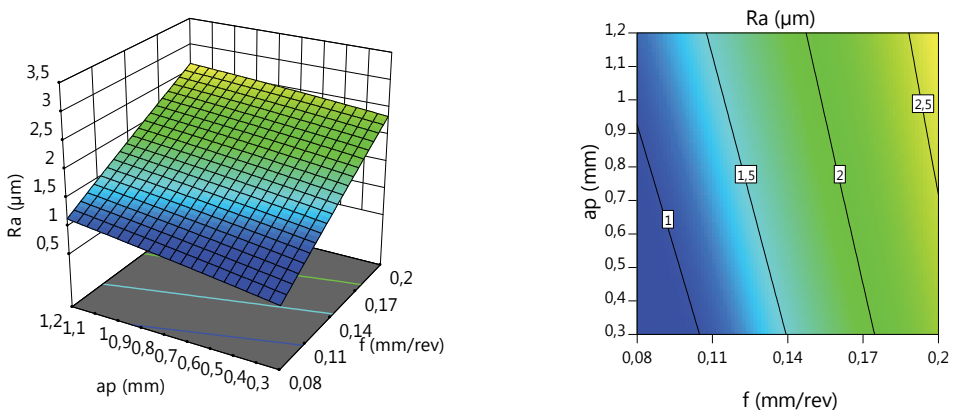

Fig. 17. Effect of depth of cut and feed rate on surface roughness, with cutting speed $V_{c}=245 \mathrm{~m} / \mathrm{min}$ 


\subsubsection{Analysis with 3D surface topography}

The representative examples of 3D surface topography of turned free-cutting steel AISI 12L14 are visualized by means of two isometric views and contour maps (Figs.(19a, 19b)). It must be noted that the both 3D profiles have represented pure roughness values, i.e. the turned surface topography in Figs.(19a, $19 \mathrm{~b}$ ) shows well-defined peaks and valleys, this is mainly because when the turning operation process uses a single cutting edge generates helicoids furrows the result of tool shape and helicoids movement tool-workpiece. The 2D surface profiles of the turned surfaces along the feed direction are shown in Figs.19(a, b). It must be noted that all the 2D profiles have represented pure roughness values, i.e. the waviness components have been filtered out.The roughness profile is measured on machined surface machining the ISO 4287/88 standard and 3D surface state parameters (Sa) which corresponds to the ISO 25178 standard. The surface workpiece topography sampling is carried out by the acquisition of regular equidistant points on a squared.
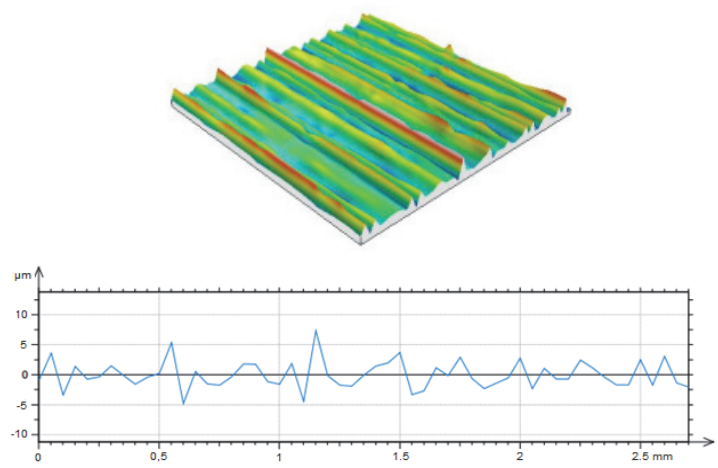

(a) $\mathrm{r}=0.4 \mathrm{~mm}$. $\mathrm{V}_{\mathrm{c}}=345 \mathrm{~m} / \mathrm{min}$. $\mathrm{f}=0.12 \mathrm{~mm} / \mathrm{rev}$ and $\mathrm{a}_{\mathrm{p}}=1.2 \mathrm{~mm}$
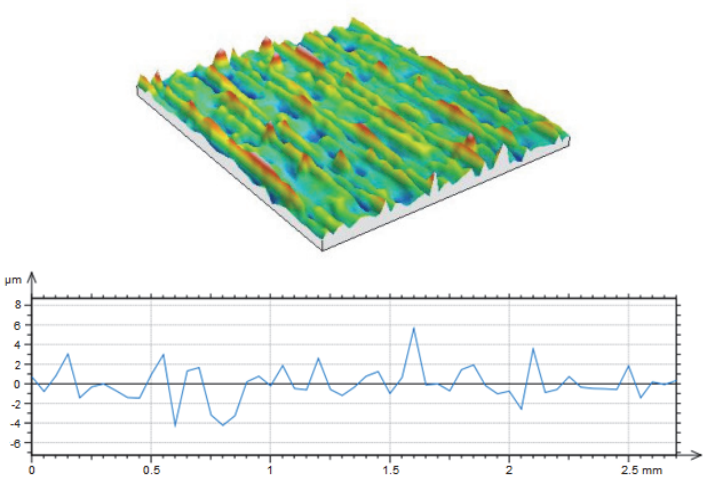

(b) $\mathrm{r}=0.4 \mathrm{~mm}$. $\mathrm{V}_{\mathrm{c}}=170 \mathrm{~m} / \mathrm{min}$. $\mathrm{f}=0.08 \mathrm{~mm} / \mathrm{rev}$ and $\mathrm{a}_{\mathrm{p}}=0.8 \mathrm{~mm}$

Fig. 18. Topographies of machined surfaces of turned AISI 12L14 free-cutting steel

\subsubsection{Effect on cutting force}

Fig. 20 representing the interaction effects of $f$ and $V_{c}$ on the cutting force shows a total dominance of the effect of the feed rate factor f over the cutting speed. The graph clearly shows that, at a given depth of cut, the tangential cutting force increases with feed rate, while it barely increases with the cutting speed. The ANOVA analysis of $F_{c}$ confirms this by suggesting the irrelevance of the combined effect, which means a dominance of one of the main factors in relation to the other. Figs. $(21,22)$ show an obvious fact that the tangential force increases with the depth of cut. Fig. 21, particularly shows that this rise go higher as the feed grows. In fact, a deeper pass associated with a higher feed rate increases the area of cutting action, which therefore requires an additional effort to be deployed.
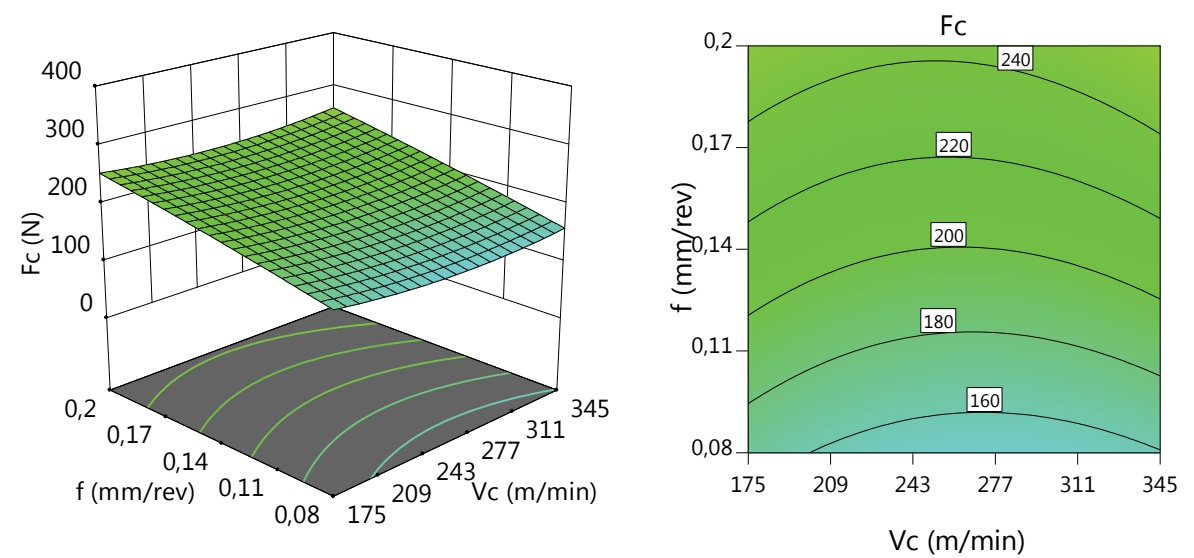

Fig. 20. Effect of cutting speed and feed rate on cutting force, with depth of cut $\mathrm{a}_{\mathrm{p}}=0.8 \mathrm{~mm}$ 

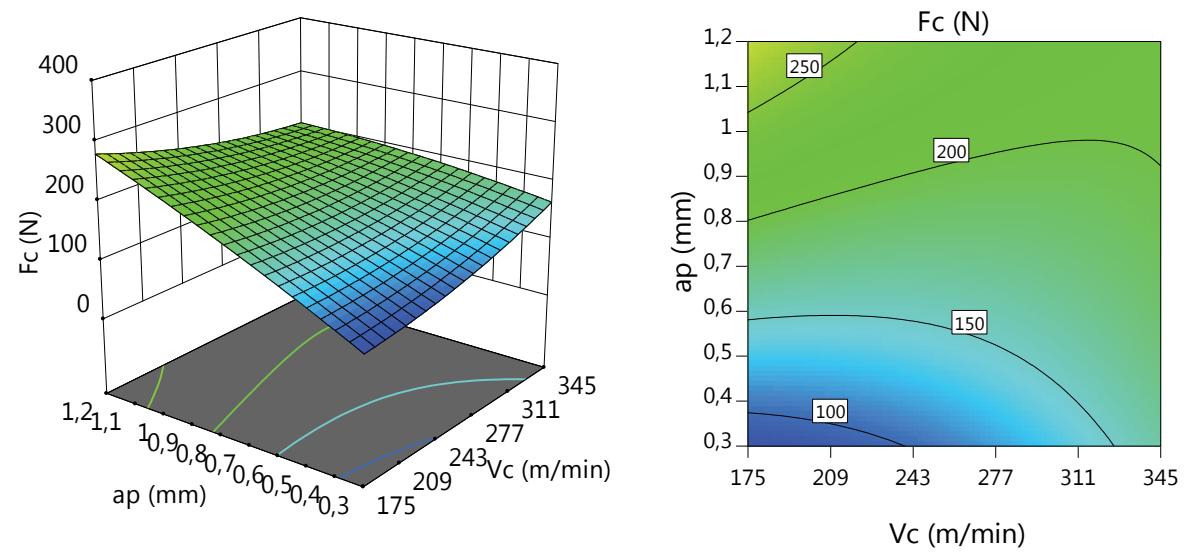

Fig. 21. Effect of cutting speed and depth of cut on cutting force, with feed rate $f=0.12 \mathrm{~mm} / \mathrm{rev}$
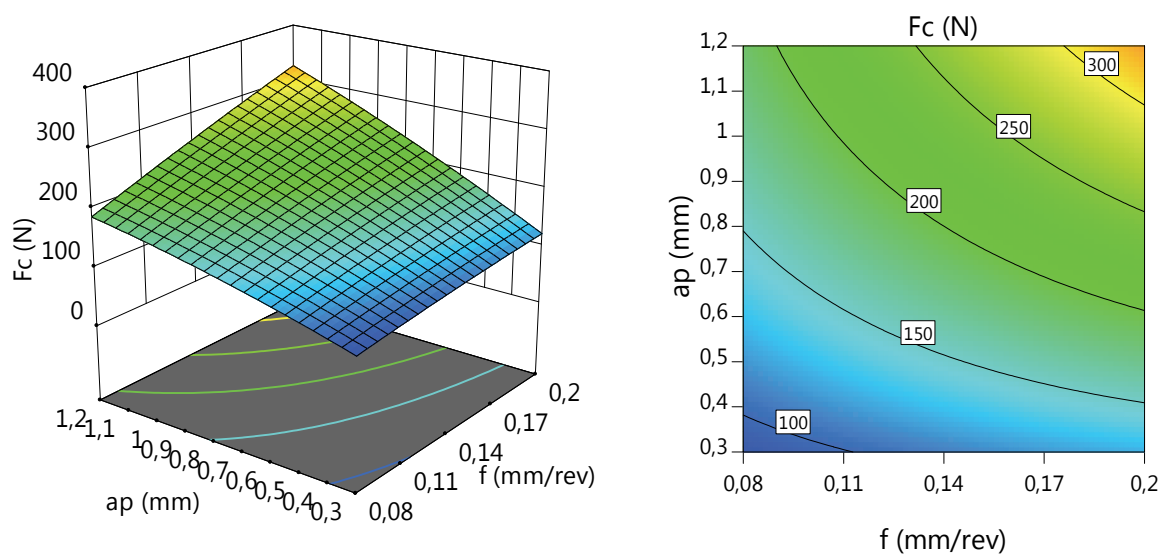

Fig. 22. Effect of depth of cut and feed rate on cutting force, with cutting speed $V_{c}=245 \mathrm{~m} / \mathrm{min}$

From Fig. 21, it can also be seen that the cutting force increases slightly with the cutting speed for the small depths. This can be explained by the strain hardening process (Xu et al., 2012). Nevertheless, beyond the depth of $0.84 \mathrm{~mm}$, the cutting force decreases a little with the cutting speed, In fact, with the increase in cutting speed, the local contact heat caused by the friction increases, which locally soften the dispersed lead particles of the metal and facilitates the chip removal. The softened insoluble lead's particles associated with sulfides will act as a lubricant film, which avoid chip adherence on the tool (Early, 1984). Additionally, in high speed the chip-tool interface may arise adiabatic shear and mutation slip, which inhibits the strain hardening process (Xu et al., 2012).

\subsubsection{Effect on material removal rate}

From the 3D and 2D graphs of the interactions (Figs.(23-25)), it can be seen that the material removal rate increases when both the cutting speed $V_{c}$, the feed rate $f$ and the depth of cut $a_{p}$ are increasing. This fact is obvious because the MRR results from the product of these three parameters. Therefore, in order to maximize the productivity, without taking into account the requirements of surface quality and cutting power consumption, it is necessary to have the combination of the largest values of the parameters $V_{c}, f$ and $\mathrm{a}_{\mathrm{p}}$. 

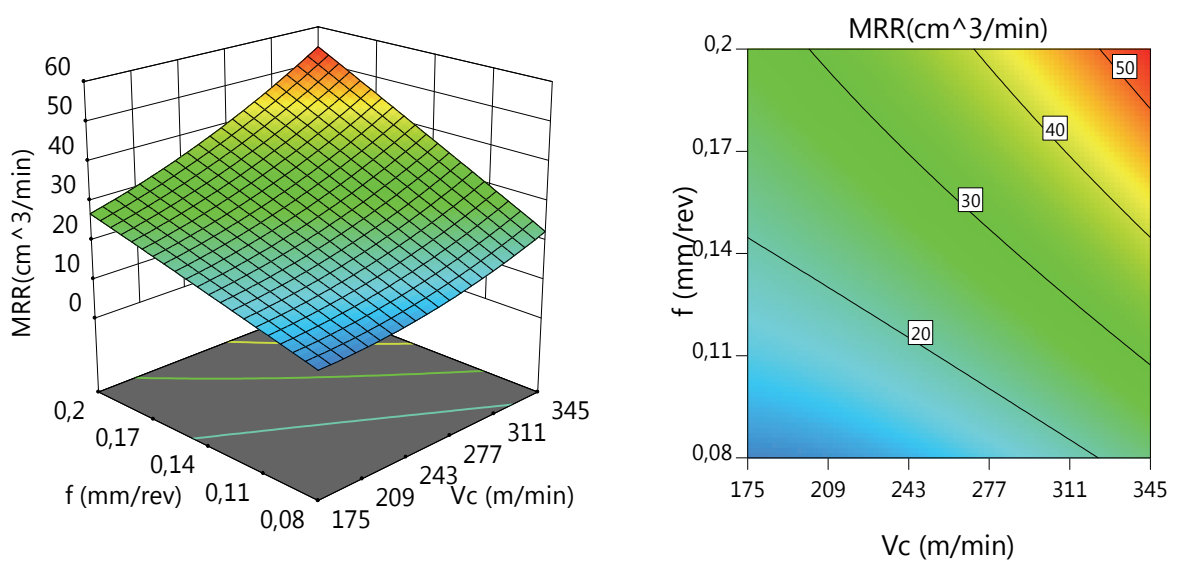

Fig. 23. Effect of cutting speed and feed rate on material removal rate, with depth of cut $\mathrm{a}_{\mathrm{p}}=0.8 \mathrm{~mm}$
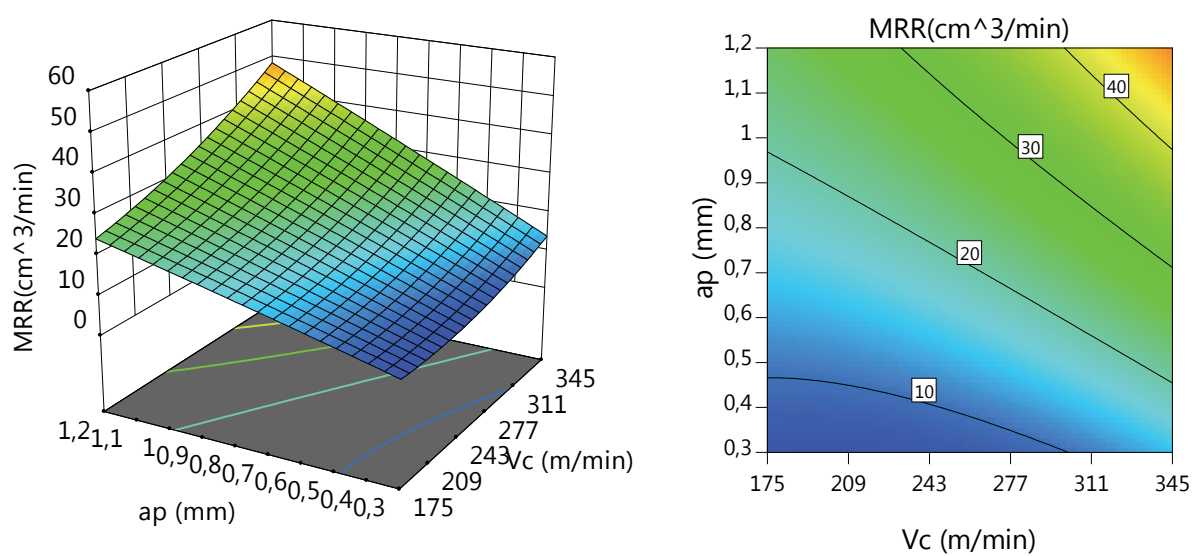

Fig. 24. Effect of cutting speed and depth of cut on material removal rate, with feed rate $\mathrm{f}=0.12 \mathrm{~mm} / \mathrm{rev}$
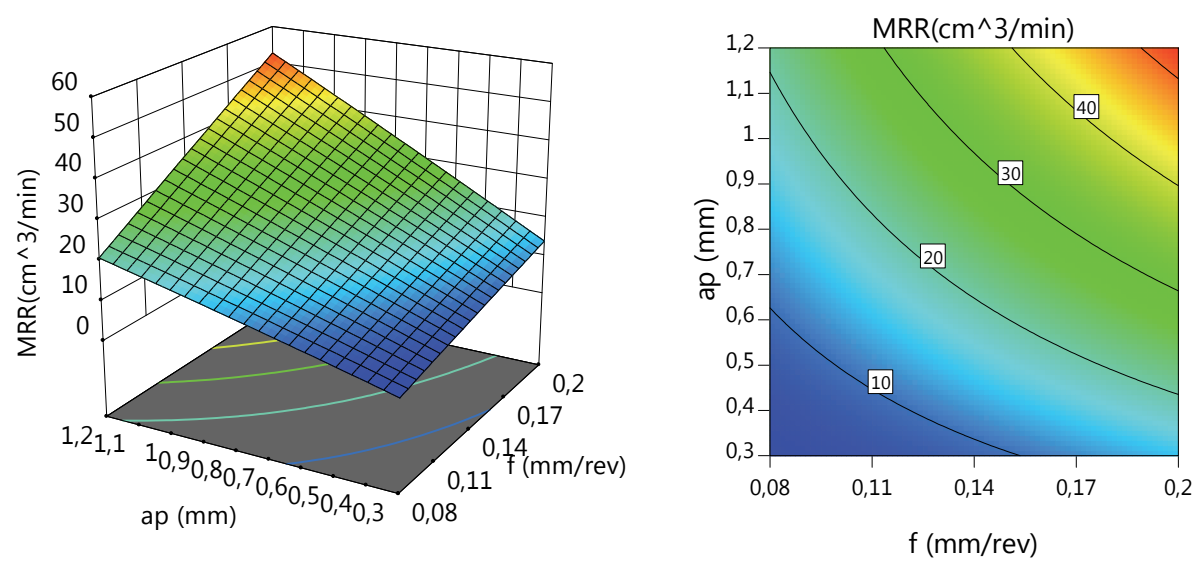

Fig. 25. Effect of depth of cut and feed rate on material removal rate, with cutting speed $V_{c}=245 \mathrm{~m} / \mathrm{min}$

\subsubsection{Effect on cutting power}

According to all interaction graphs (Figs.(26-28)), the cutting power reach its maximum at highest cutting parameters values when $a_{p}$, f and $V_{c}$ are at their maximum. Since, at higher cutting parameters, the cutting tool opposes more frictional resistance from the work material, which increases the necessary power to chip removal. From the $3 \mathrm{D}$ and contour graphs (Fig. 26) of the $\mathrm{V}_{\mathrm{c}}$ - f interaction effects on the cutting power, it is well observed that the combined effect of these two parameters is positively significant. Thus, 
their increase leads to cutting power assent. The slops of the iso-values domains shows that the effect of the feed rate rises up with the extent of the cutting speed level. The interaction between the effect of the cutting speed and the depth of cut (Fig.27) is significant. The cutting power increases with the increase of both of the two parameters. It is also noted, when the graph is swept horizontally, that the lower the cutting speed goes, the greater the effect of the depth of cut becomes. In the same way, when the graph is swept horizontally, it can be noted that the lower the depth of cut goes, the greater the effect of the cutting speed will be. Indeed, the power depends positively on both $\mathrm{V}_{\mathrm{c}}$ and $\mathrm{F}_{\mathrm{c}}$ (Eq.(2)). Whereas, according to the analysis of the effects of the main parameters (Table 6) and the interactions (Figs.(21, $22)$ ), the cutting force $\left(F_{c}\right)$ essentially depends on the depth of the cut. Thus, at a given level of cutting power, when the depth of cut is at its minimum in other words, the cutting force is minimal-, the effect of its variation on the power will be negligible; and the cutting speed contribution will take over. Then, in the opposite case, that is, when the cutting speed is low, its own impact will be reduced and the effect of the variation in the depth of cut will have more influence on cutting power. According to this graphical analysis, the goal of minimizing the consumed cutting power, regardless of the productivity and quality constraints, is attaint when all the input cutting parameters are at their minimum values.
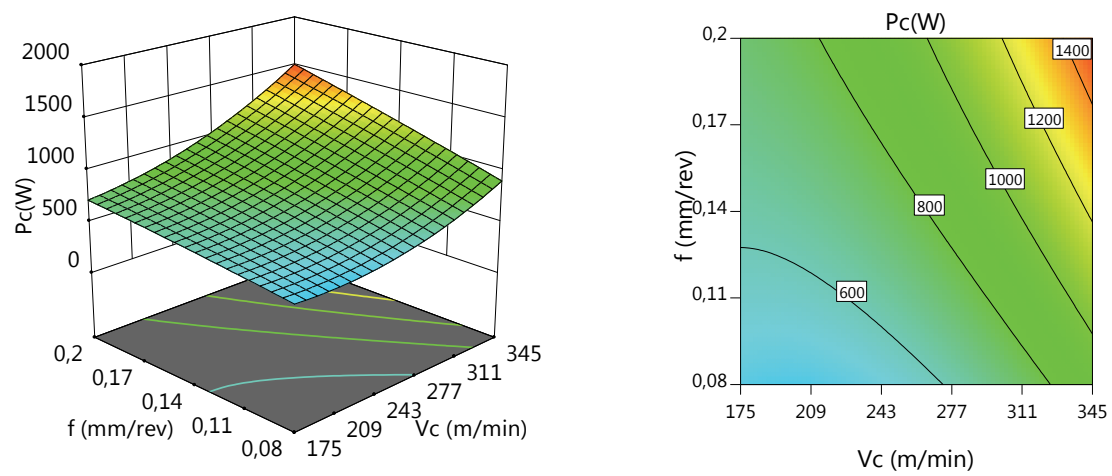

Fig. 26. Effect of cutting speed and feed rate on cutting power, with depth of cut $a_{p}=0.8 \mathrm{~mm}$
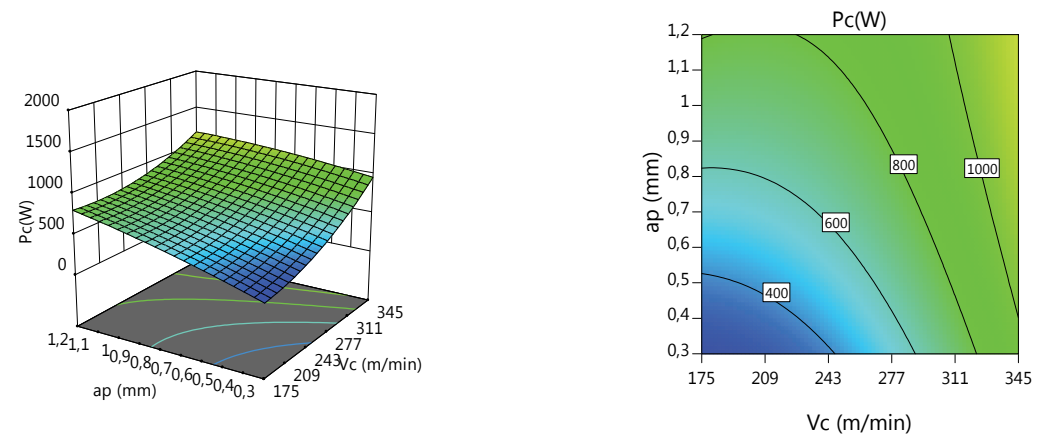

Fig. 27. Effect of cutting speed and depth of cut on cutting power, with feed rate $f=0.12 \mathrm{~mm} / \mathrm{rev}$
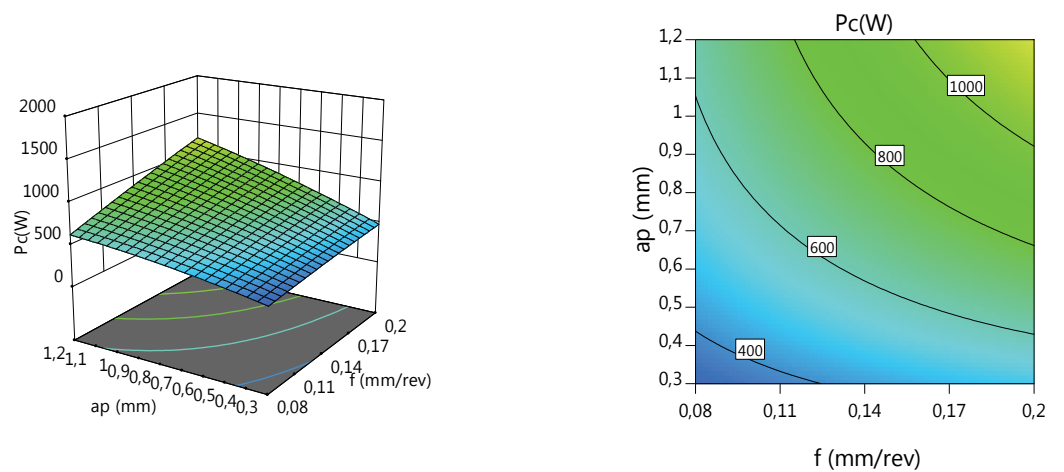

Fig. 28. Effect of depth of cut and feed rate on cutting power, with cutting speed $V_{c}=245 \mathrm{~m} / \mathrm{min}$ 


\subsection{Confirmation tests}

With the optimal process parameter identified, the confirmation test is performed to validate the analysis. During the validation test, an experiment was carried out with an optimal adjustment of the process parameters. Table 9 and Table 10 show the comparison of the surface roughness and cutting force values obtained experimentally with the predicted value of RSM. The results of the confirmation test and their comparisons with the predicted values for Ra and Fc are listed in Tables (9-10). The results reveal a small percentage of error. The percentage error range between the actual and predicted value of Ra lies between $1 \%$ and $9 \%$, and $\mathrm{Fc}$ lies in the range of $3.4 \%$ to $7 \%$.

Table 9

Conformation test values of surface roughness $(\mathrm{Ra})$

\begin{tabular}{|c|c|c|c|c|c|c|}
\hline \multirow[b]{2}{*}{ Test } & & & & \multirow{2}{*}{$\begin{array}{c}\text { Experimental } \\
R a(\mu m)\end{array}$} & \multirow{2}{*}{$\begin{array}{c}\text { Predicted } \\
R a(\mu \mathrm{m})\end{array}$} & \multirow[b]{2}{*}{ Error (\%) } \\
\hline & $\begin{array}{c}V_{c} \\
(\mathrm{~mm} / \mathrm{min})\end{array}$ & $\begin{array}{c}f \\
(\mathrm{~mm} / \mathrm{rev})\end{array}$ & $\begin{array}{c}a_{p} \\
(\mathrm{~mm})\end{array}$ & & & \\
\hline 1 & 345 & 0.08 & 1 & 1.55 & 1.61 & 7.6 \\
\hline 2 & 345 & 0.12 & 1 & 2.2 & 2.15 & 2.2 \\
\hline 3 & 175 & 0.1 & 0.8 & 1.7 & 1.68 & 1.0 \\
\hline 4 & 175 & 0.1 & 1.2 & 1.85 & 1.79 & 3.2 \\
\hline 5 & 195 & 0.2 & 1 & 2.6 & 2.75 & 5.8 \\
\hline 6 & 345 & 0.2 & 1 & 3.5 & 3.18 & 9.0 \\
\hline
\end{tabular}

Table 10

Conformation test values of cutting force $(\mathrm{Fc})$

\begin{tabular}{|c|c|c|c|c|c|c|}
\hline Test & $\begin{array}{c}V_{c} \\
(\mathrm{~mm} / \mathrm{min})\end{array}$ & $\begin{array}{c}f \\
(\mathrm{~mm} / \mathrm{rev})\end{array}$ & $\begin{array}{c}a_{p} \\
(\mathrm{~mm})\end{array}$ & $\begin{array}{c}\text { Experimental } \\
F c(N)\end{array}$ & $\begin{array}{c}\text { Predicted } \\
F_{c}(N)\end{array}$ & Error (\%) \\
\hline 1 & 345 & 0.08 & 1 & 145.4 & 153.65 & 5.7 \\
\hline 2 & 345 & 0.12 & 1 & 187.5 & 199.69 & 6.5 \\
\hline 3 & 170 & 0.1 & 0.8 & 188.6 & 181.32 & 3.9 \\
\hline 4 & 170 & 0.1 & 1.2 & 240.2 & 257.07 & 7.0 \\
\hline 5 & 195 & 0.2 & 1 & 285.2 & 294.79 & 3.4 \\
\hline 6 & 345 & 0.2 & 1 & 295.5 & 284.26 & 3.8 \\
\hline
\end{tabular}

\section{Optimization using desirability function approach}

The desirability function approach is employed in this study for the optimization of multiple response problems. This method was first proposed by Harrington (Harrington, 1965) and popularized by Derringer (Saidi et al., 2018). It is based on the idea that the "quality" of a process that has multiple responses, with one of them outside of some "desired" limits, is completely undesirable. The method finds operating conditions $\mathrm{x}$ that provide the "most desirable" response values. For each response $\mathrm{Y}_{\mathrm{i}}(\mathrm{x})$, a desirability function $\operatorname{di}\left(Y_{i}\right)$ attributes numbers between 0 and 1 to the plausible values of $Y_{i}$. If $d_{i}\left(Y_{i}\right)=$ 0 the value of $\mathrm{Y}_{\mathrm{i}}$ is imperatively unwanted and if $\operatorname{di}\left(\mathrm{Y}_{\mathrm{i}}\right)=1$ the value of $\mathrm{Y}_{\mathrm{i}}$ is completely desirable. The overall desirability $\mathrm{D}$ is given to combine the individual desirability with the help of the geometric mean:

$$
\left.\mathrm{D}=\left(\mathrm{d}_{1} \times \mathrm{d}_{2} \times \ldots \ldots \times \mathrm{d}_{\mathrm{n}}\right)^{(1 / \mathrm{n})}=\sum_{\mathrm{n}=1}^{\mathrm{n}} \mathrm{d}_{\mathrm{i}}^{(1 / \mathrm{n})}\right)
$$

where $n$ represent the number of responses. For simultaneous optimization, both responses should have a low and high value attributed to each objective. For the maximum search, desirability is rewritten as follows:

$$
\left\{\begin{array}{l}
d_{i}=0 \quad \text { if response } \prec \text { low value } \\
0 \leq d_{i} \leq 1, \text { as response var ies from low to high } \\
d_{i}=1 \quad \text { f response } \succ \text { high value }
\end{array}\right.
$$

If a response is to be minimized instead, the individual desirability is defined as:

$$
\left\{\begin{array}{l}
d_{i}=1 \quad \text { if response } \prec \text { low value } \\
1 \geq d_{i} \geq 0 \text { as response var ies from low to high } \\
d_{i}=0 \quad \text { f response } \succ \text { high value }
\end{array}\right.
$$


Our optimization object, here, is to determine the optimum cutting conditions to achieve maximum surface quality and productivity while keeping in mind to consume as little as possible of the cutting power. However, before performing a multi-objective optimization, we will first look for optimums one by one, in order to observe the affinities and the contradictory effects and to determine the degree of importance of each one in the process of combined (multi-objective) optimization. The results of the single-objective optimizations are gathered in the Table 8. From these results, it can be inferred that the criterion of maximum productivity affects negatively the surface quality and leads to excessive consumption of power. Otherwise, the criterion of minimizing energy consumption, essentially, affects productivity. Among these two economic criteria (i,e, , it is necessary to choose which one is the most important to consider in the execution of the multi-objective optimization. It should be considered, as constraint, that the surface quality is not to be compromised at any circumstance. In this case, of study, productivity is highly constraining for the other two criteria, so it will take the least importance. However, since it is very important in the modern industrial processes, it should be considered in the roughing operations, because the product, at this stage, is not finished yet. Nevertheless, energy consumption is not to be sacrificed, as it is a high standing contemporary issue in modern manufacturing, for its influence on the overall cost and the environmental impact. Table 11 summarizes all the criteria for the multiresponse optimization under constraints, whose objective functions are: (1) minimizing the roughness, (2) minimizing the consumption of the cutting power, and (3) maximizing the material removal rate. The constraint is that all parameters must be included in the intervals of the given experimental domain.

Table 11

Summary of values obtained for the three individual cases of optimization

\begin{tabular}{cccccccc}
\hline Optimization & $V_{c}$ & $f$ & $a_{p}$ & $R_{a}$ & $P_{c}$ & MRR & Desirability \\
\hline Quality & 278.057 & 0.083 & 0.304 & 0.649 & 469.922 & 4.228 & 1.000 \\
Low power consumption & 175.000 & 0.2 & 0.300 & 2.946 & 205.343 & 9.107 & 0.990 \\
Productivity & 337.735 & 0.189 & 1.170 & 3.034 & 1584.118 & 68,667 & 1.000 \\
\hline
\end{tabular}

Table 12

Goals and parameter ranges for optimization of cutting conditions

\begin{tabular}{|c|c|c|c|c|c|c|}
\hline \multicolumn{7}{|c|}{ Constraints } \\
\hline Name & Goal & $\begin{array}{c}\text { Lower } \\
\text { Limit }\end{array}$ & $\begin{array}{l}\text { Upper } \\
\text { Limit }\end{array}$ & $\begin{array}{l}\text { Lower } \\
\text { Weight }\end{array}$ & $\begin{array}{l}\text { Upper } \\
\text { Weight }\end{array}$ & Importance \\
\hline$V_{c}$ & is in range & 175 & 345 & 1 & 1 & 3 \\
\hline$f$ & is in range & 0.08 & 0.2 & 1 & 1 & 3 \\
\hline$a_{p}$ & is in range & 0.3 & 1.2 & 1 & 1 & 3 \\
\hline$R_{a}$ & minimize & 0.914 & 3.17 & 1 & 1 & 5 \\
\hline$P_{c}$ & minimize & 191.533 & 1585.85 & 1 & 1 & 5 \\
\hline$M R R$ & maximize & 4.08 & 55.2 & 1 & 1 & 1 \\
\hline
\end{tabular}

The optimal solutions are represented in the Table 13 , giving the highest desirability value $(0.762)$. The ramp function graph (Fig. 29) shows the optimization results at a selected point among the highest desirable, which located according to contour plots (Fig. 30) at the lowest level of feed rate $f$ and at the mid-range of the depth of cut. The optimal cutting conditions, at this selected point, are found to be as follows: $\mathrm{V}_{\mathrm{c}}=245.149 \mathrm{~m} / \mathrm{min}, \mathrm{f}=0.08 \mathrm{~mm} / \mathrm{rev}$ and $\mathrm{a}_{\mathrm{p}}=0.790 \mathrm{~mm}$. The corresponding optimized Results for the roughness, the cutting power consumption and the material removal rate are $R_{a}=0.910 \mu \mathrm{m}$, $\mathrm{P}_{\mathrm{c}}=503.391 \mathrm{~W}$ and $\mathrm{MRR}=13.243 \mathrm{~cm}^{3} / \mathrm{min}$, respectively.

Table 13

Responses for Ra, Fc, Pc and MRR for optimization of cutting conditions

\begin{tabular}{ccccccc}
\hline Number & $V_{c}$ & $f$ & $a_{n}$ & $R_{a}$ & $P_{c}$ & MRR \\
\hline 1 & 245.149 & 0.080 & 0.790 & 0.910 & 503.391 & 13.243 \\
2 & 245.431 & 0.080 & 0.791 & 0.910 & 504.197 & 13.277 \\
3 & 244.515 & 0.080 & 0.788 & 0.910 & 501.533 & 13.164 \\
4 & 243.911 & 0.080 & 0.786 & 0.910 & 499.760 & 13.089 \\
5 & 243.033 & 0.080 & 0.782 & 0.910 & 497.095 & 12.974 \\
6 & 241.790 & 0.080 & 0.777 & 0.910 & 493.255 & 12.809 \\
7 & 248.422 & 0.080 & 0.800 & 0.910 & 512.549 & 13.624 \\
8 & 245.218 & 0.080 & 0.786 & 0.910 & 502.704 & 13.193 \\
1 & 247.471 & 0.080 & 0.791 & 0.907 & 507.958 & 13.394 \\
11 & 241.729 & 0.080 & 0.783 & 0.913 & 495.159 & 12.921 \\
12 & 238.983 & 0.080 & 0.763 & 0.910 & 484.062 & 12.410 \\
\end{tabular}



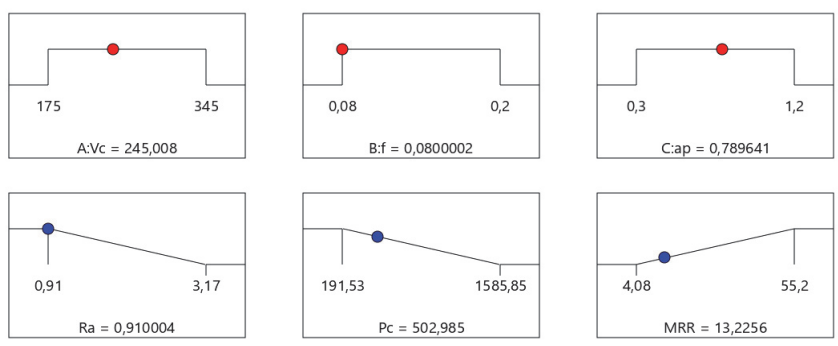

Desirability $=0,762$

Fig. 29. Ramp function graph for cutting force components and Ra, Fz, Pc and MRR combined optimization
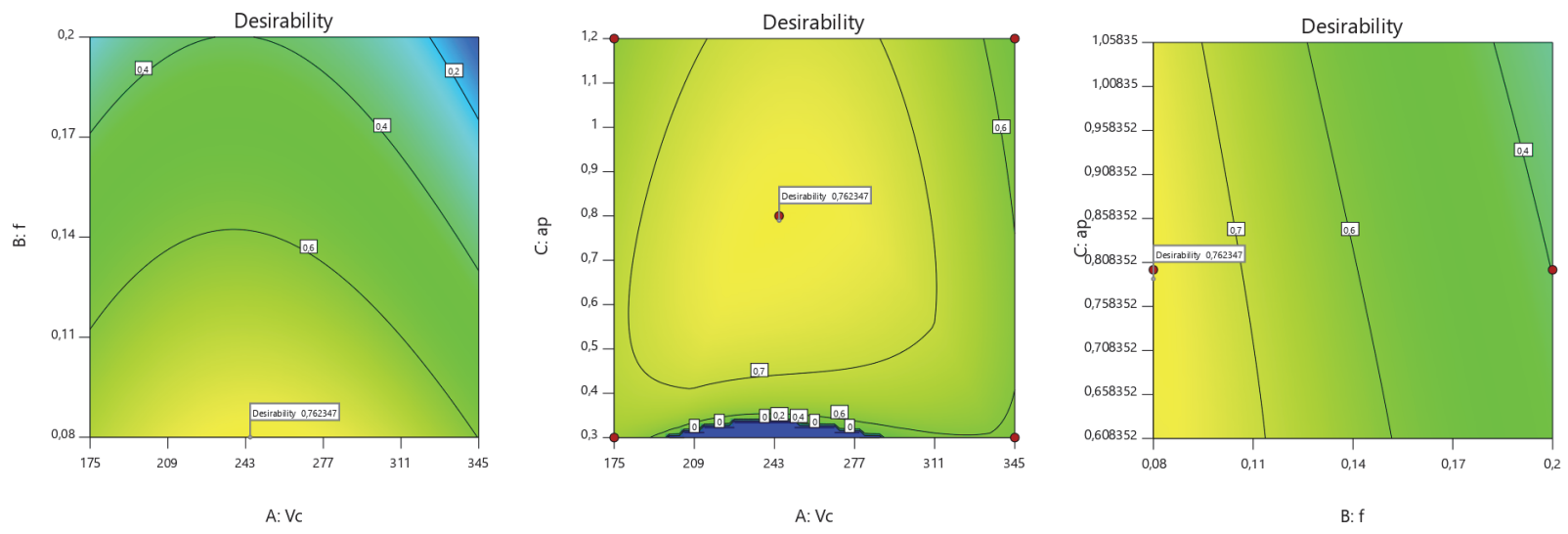

Fig. 30. Desirability contours graphs of optimization

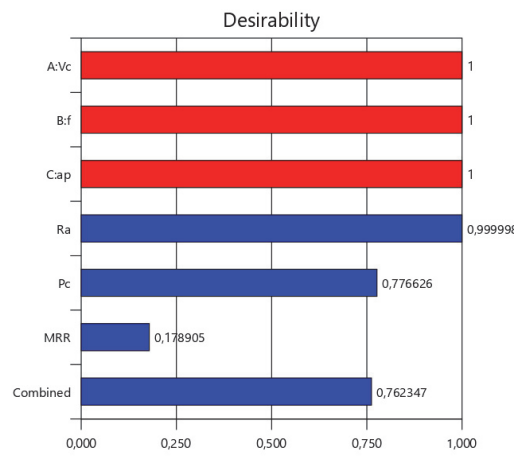

Fig. 31. Bar graph of desirability for combined optimization

\section{Conclusion}

This study aimed to determine the optimal cutting parameters leading to maximum surface quality (lowest arithmetic roughness) with minimum cutting power, adding to a maximum of material removal rate of free-cutting steel (AISI 12L14) finish turning process. The main findings inherent in this study can be highlighted as follows:

The ANOVA analysis results for Ra revealed that the most prominent factor is the feed rate $\mathrm{f}$ with a contribution of $74.25 \%$ followed by the depth of cut $\mathrm{a}_{\mathrm{p}}$ and the product of cutting speed $\mathrm{V}_{\mathrm{c}}{ }^{2}$ with $7.18 \%$ and $10.69 \%$ significances, respectively. The analyses, also, showed that the cutting power Pc is mainly affected by $\mathrm{V}_{\mathrm{c}}$, which represents the major component in its theoretical expression with $37.41 \%$ of contribution. The $a_{p}$ and $f$ contributions are $28.14 \%$ and $15.17 \%$, respectively. The cutting force as a second component in the cutting power expression seemed to be highly affected by the depth of cut with 
$51.39 \%$ of influence than by the feed rate with $16.3 \%$. For the material removal rate MRR, the depth of cut with $55.51 \%$ of the contribution, was proven as the most influential parameter. The feed rate and the cutting speed came next, respectively, by $25.51 \%$ and $16.23 \%$ of contribution. With very close to "1" correlation coefficients $\left(\mathrm{R}^{2}\right)$ and graphically proven normality and significance, the developed models are confirmed as highly reliable to be able to predict responses accurately. Within the given experimental design space. According to the graphical analyses of the interactions, the following results were carried. For a better surface quality without taking account of the constraints of productivity and energy consumption, it is necessary that the feed rate and the depth of cut be set at their minima with an average cutting speed within the experimental area. For lower cutting power consumption regardless of the productivity and quality constraints, the cutting speed $\mathrm{V}_{c}$, the feed rate $f$ and the depth of cut $a_{p}$ must be at their minimum values. For maximum productivity without taking into account the requirements of quality and consumption of the cutting power, it is necessary to have the combination of the largest values of the parameters $\mathrm{V}_{\mathrm{c}}$. f and $\mathrm{a}_{\mathrm{p}}$. As a result from the mono objective optimizations, the higher productivity, which required the largest values of the parameters $V_{c}, f$ and $a_{p}$, was in total contrast with the high quality of surface and the minimum cutting power consumption. Therefore, it was lowly weighted for the multiobjective optimization, to have convenient results with high desirability values. The global optimization, combining high surface quality and productivity with low cutting power consumption, gave 12 optimal setting points providing high desirability values, within the experimental domain.

\section{Acknowledgments}

This work was achieved in the laboratories LMMP University of Tunis, ENSIT, Tunisia and MAI University of Tunis El Manar, ENIT, Tunisia in collaboration with LMS laboratory Guelma University, Algeria. The authors would like to thank the financial support from the JMS flexible, MGHIRA TUNISIA.

\section{References}

Bhattacharya, D., \& Quinto, D. T. (1980). Mechanism of hot-shortness in leaded and tellurized freemachining steels. Metallurgical Transactions A, 11(6), 919-934.

Bouchelaghem, H., Yallese, M. A., Mabrouki, T., Amirat, A., \& Rigal, J. F. (2010). Experimental investigation and performance analyses of $\mathrm{CBN}$ insert in hard turning of cold work tool steel (D3). Machining Science and Technology, 14(4), 471-501.

Bouzid, L., Boutabba, S., Yallese, M. A., Belhadi, S., \& Girardin, F. (2014). Simultaneous optimization of surface roughness and material removal rate for turning of $\mathrm{X} 20 \mathrm{Cr} 13$ stainless steel. The International Journal of Advanced Manufacturing Technology, 74(5-8), 879-891.

Costa, D. M. D., Paula, T. I., Silva, P. A. P., \& Paiva, A. P. (2016). Normal boundary intersection method based on principal components and Taguchi's signal-to-noise ratio applied to the multiobjective optimization of 12L14 free machining steel turning process. The International Journal of Advanced Manufacturing Technology, 87(1-4), 825-834.

Das, I., \& Dennis, J. E. (1998). Normal-boundary intersection: A new method for generating the Pareto surface in nonlinear multicriteria optimization problems. SIAM Journal on Optimization, 8(3), 631-657.

de Freitas Gomes, J. H., Júnior, S., Ramos, A., de Paiva, A. P., Ferreira, J. R., da Costa, S. C., \& Balestrassi, P. P. (2012). Global Criterion Method Based on Principal Components to the Optimization of Manufacturing Processes with Multiple Responses. Strojniski Vestnik/Journal of Mechanical Engineering, 58(5), 345-353.

Dureja, J. S., Gupta, V. K., Sharma, V. S., \& Dogra, M. (2010). Design optimisation of flank wear and surface roughness for CBN-TiN tools during dry hard turning of hot work die steel. International Journal of Machining and Machinability of Materials, 7(1-2), 129-147.

Early, J. G. (1984). Mechanical Properties of a Leaded, Resulfurized, Rephosphorized Steel in Various Thermo/Mechanical Conditions.

Fnides, B., Yallese, M. A., Mabrouki, T., \& Rigal, J. F. (2011). Application of response surface methodology for determining cutting force model in turning hardened AISI H11 hot work tool steel. Sadhana, 36(1), 109.

Harrington, Edwin C. J. (1965). ASQ: The Desirability Function. 
Hwang, Y. K., \& Lee, C. M. (2010). Surface roughness and cutting force prediction in MQL and wet turning process of AISI 1045 using design of experiments. Journal of Mechanical Science and Technology, 24(8), 1669-1677.

Kandananond, K. (2009). The determination of empirical model for surface roughness in turning process using design of experiment. WSEAS Transactions on Systems, 8(10).

Kandananond, K. (2010). Using the response surface method to optimize the turning process of AISI 12L14 steel. Advances in Mechanical Engineering, 2, 362406.

Kishawy, H. A., Hosseini, A., Moetakef-Imani, B., \& Astakhov, V. P. (2012). An energy based analysis of broaching operation: Cutting forces and resultant surface integrity. CIRP annals, 61(1), 107-110.

Luiz, N. E., \& Machado, Á. R. (2008). Development trends and review of free-machining steels. Proceedings of the Institution of Mechanical Engineers, Part B: Journal of Engineering Manufacture, 222(2), 347-360.

Meddour, I., Yallese, M. A., Khattabi, R., Elbah, M., \& Boulanouar, L. (2015). Investigation and modeling of cutting forces and surface roughness when hard turning of AISI 52100 steel with mixed ceramic tool: cutting conditions optimization. The International Journal of Advanced Manufacturing Technology, 77(58), 1387-1399.

MEHANSKE, A. V. T. O. N., \& JEKEL, L. A. (2016). Analyzin the heat-treatment effect on the mechanical properties of free-cutting steels. Materiali in tehnologije, 50(3), 337-341.

Overcash, J. L., \& Cuttino, J. F. (2009). Design and experimental results of a tunable vibration turning device operating at ultrasonic frequencies. Precision Engineering, 33(2), 127-134.

Peruchi, R. S., Paiva, A. D., Balestrassi, P. P., Ferreira, J. R., \& Sawhney, R. (2014). Weighted approach for multivariate analysis of variance in measurement system analysis. Precision Engineering, 38(3), 651-658.

Pierson, G. (1989). Les aciers doux de décolletage: évolutions des procédés et des performances sur produits. Revue de Métallurgie, 86(9), 707-724.

Reis, L. L., Silva Júnior, W. M. D., \& Machado, Á. R. (2007). Effect of cutting speed and cutting fluid on the BUE geometry of a SAE 12L14 free machining steel. Journal of the Brazilian Society of Mechanical Sciences and Engineering, 29(2), 196-201.

Roelofs, H., Boeira, A. M. G., Margot, R., Gomes, J. T., \& Eglin, M. (2008). Machinability of inclusion engineered free cutting steel under built-up edge conditions. In 8th International Conference on Advanced Manufacturing Systems and Technology (AMST2008). Unknown.

Saidi, R., Fathallah, B. B., Mabrouki, T., Belhadi, S., \& Yallese, M. A. (2018). Modeling and optimization of the turning parameters of cobalt alloy (Stellite 6) based on RSM and desirability function. The International Journal of Advanced Manufacturing Technology, 100(9-12), 2945-2968.

Sarıkaya, M., \& Güllü, A. (2014). Taguchi design and response surface methodology based analysis of machining parameters in CNC turning under MQL. Journal of Cleaner Production, 65, 604-616.

Selvakumar, S., Kumar, R. R., \& Ganesan, K. (2015). Analysis and optimisation of machining parameters in micro turning using RSM. International Journal of Materials and Product Technology, 51(1), 75-97.

Song, S. Q., \& Zuo, D. W. (2014). Modelling and simulation of whirling process based on equivalent cutting volume. Simulation Modelling Practice and Theory, 42, 98-106.

Tebassi, H., Yallese, M., \& Meddour, I. (2016). A new method for evaluation nominal coefficient of friction and frictional forces in turning and inserts characterization using cutting forces profiles. Engineering Solid Mechanics, 4(1), 1-10.

Thangavel, P., \& Selladurai, V. (2008). An experimental investigation on the effect of turning parameters on surface roughness. IJMR, 3(3), 285-300.

Xu, J. Y., An, Q. L., \& Chen, M. (2012). Experimental study on high-speed turning of free-cutting steel AISI 12L14 using multi-layer coated carbide tools. Advanced Materials Research, 500, 3-7.

Yaguchi, H., \& Bhattacharya, D. (1988). An investigation of factors controlling part growth and surface finish of form tools in the automatic screw machine test. Journal of Materials Shaping Technology, 5(4), 231241.

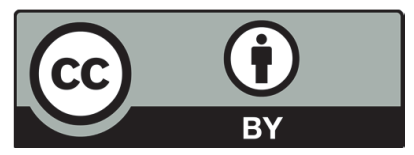

(C) 2019 by the authors; licensee Growing Science, Canada. This is an open access article distributed under the terms and conditions of the Creative Commons Attribution (CCBY) license (http://creativecommons.org/licenses/by/4.0/). 